\title{
Corruption, Social Infrastructure and their Role in Shaping Sustainable Development
}

\author{
Noha Mahmoud Ashraf Moamed Ali Zaitoun \\ $\mathrm{PhD}$ in Economics \\ Economic Department \\ Faculty of Commerce \\ Zagazig University \\ Arab Republic of Egypt
}

\begin{abstract}
This paper aims at studying the impact of corruption, as one of the most important features that shape a country's social infrastructure, on sustainable development, within the framework of institutional quality (good governance). In order to overcome the problem of the omitted variable bias, an extensive research was carried out into the possibility that corruption could boost economic efficiency at the country level. In other words, the study investigates whether or not the "Greasing the wheels" hypothesis is actually realized in the relationship between corruption and sustainable development. Using three different approaches, deducted from previous studies and based on the "fixed effects" and the "dynamic Panel data" methods, the study concluded that a good social infrastructure, including efficient institutions and policies, is considered one of the main pillars for achieving sustainable development. It was also found that transparency and low corruption levels represent crucial factors for shaping social infrastructure and raising the level of sustainable development. In contrast to those robust results, mixed evidence was found about the extent of the "Greasing the wheels" hypothesis validity, although most findings supported the inability of corruption to boost economic efficiency.
\end{abstract}

Keywords: Corruption, Institutions, Good Governance, Social Infrastructure, Sustainable Development.

\section{Introduction}

Corruption represents a major challenge to sustainable development as it reflects the failure of a country's governance to provide social, judicial, political and economic checks and balances (UNDP, 2008). A wellknown scientific definition of corruption, used by most organizations, describes corruption as the "abuse of public authority to achieve private interests" (Mauro, 1995). Since the 1970s, the academic literature has abounded with studies and explanations concerning the causes and effects of corruption. Over the past two decades, awareness of the negative impact of corruption on sustainable development has been increasing, as empirical studies proved the relationship between the spread of corruption on one hand, and the deterioration of macroeconomic figures, on the other hand, such as the goals of sustainable development, poverty eradication, and social justice. Corruption undermines long-term sustainable development in a variety of ways. It hinders domestic and foreign investment due to the high cost of projects as a result of bribes while increasing opportunities to seek economic benefits without taking into account the interests of society, thus creating an atmosphere of uncertainty and reducing investment incentives (Aidt, 2011).

* This article was submitted in October 2021, and accepted for publishing in December 2021.

(c) Arab Administrative Development Organization- League of Arab States, 2024, pp 227-248، DOI: 10.21608/aja.2021.103343.1176 
In addition, corruption impedes human development as it distorts the structure of public spending by reducing the resources allocated to social programs such as health and education, while increasing the resources devoted to infrastructure and easily bribed contracts. Hence corruption has biased distributional effects against the poor. It also impairs economic efficiency since competition between companies relies no more on market rules but on the ability of each company to pay bribes. Moreover, corruption limits the State's ability to increase public revenues through promoting tax and customs evasion, as well as improper application of tax exemptions and preferential treatment (Tanzi \& Davoodi, 2000).

Besides, corruption limits the effectiveness of foreign aid and increases the size of the country's hidden economy and the level of inflation. It also threatens environmental sustainability due to the avoidance of environmental laws' implementation through bribes. In addition, corruption has many other negative political and social implications, such as the loss of the State's legitimacy, and its increased vulnerability to political and social instability, the distortion of the climate of democracy, the breakdown of moral and societal values and the interaction and intervention of corruption with organized crime. All this drove the World Bank to describe corruption as the biggest obstacle to sustainable development, as it seriously undermines the institutional structure underlying the developmental process (UNDP, 2008).

The association of corruption with all these negative phenomena does not mean that it causes them to occur. However, there is no dispute over the interdependence of corruption, sustainable development and government institutions. Therefore corruption cannot be ignored when devising policies for promoting sustainable development and good governance. Institutions play also a very important role in determining the impact of corruption on development. Hence, the political structure which includes a balance of powers and electoral competitiveness is more capable of identifying incentives that encourage office holders to be honest and to punish dishonest persons (Kuloglu et al., 2012). Therefore, as a result of the development community agreement on a causal relationship between good governance and sustainable development, corruption is increasingly seen as the result of weak governance, at a time when a unified language is being formed, linking issues of corruption with good governance and sustainable development. This paper attempts to explore the impact of corruption on sustainable development within the framework of good governance, while examining the possibility that corruption may enhance the economic efficiency of countries (Lash, 2004).

This study is organized as follows: In section (2) we discuss the theoretical framework of the study model. Section (3) reviews the previous literature relevant to the purpose of the present study. Section (4) displays the experimental specifications of the study models and the description of the study variables. In Sections (5) and (6), we present the empirical results and the econometric analysis of the model; and we discuss some of the procedures for verifying the robustness and stability of the results. Finally, Section (7) includes a summary of the results, the conclusion and recommendations for further research.

\section{Theoretical framework}

Theories of economic growth have been concerned with examining the causes of income differences across countries, in order to determine to which extent overall growth and living standards can be raised in poor countries. In that context, various theories, from classical and neoclassical to modern theories, have dug for the main determinants of economic growth, from the accumulation of fiscal capital, to investing in human capital and technological progress. However the causes of economic growth advanced by such theories failed to provide us with a unified explanation of the vast differences in income prevailing across countries. Consequently, researchers have sought to delve deeper into the matter. The main suggested hypothesis was that income differences across countries stemmed largely from differences in what Hall \& Jones (1999) called the "social infrastructure".

Social infrastructure refers to the institutions and policies that seek to reach a harmony between the private and social revenues of activities, i.e. the institutions and policies that determine the allocation of resourc- 
es between the activities which raise the gross domestic product (GDP) and those which redistribute them." Social infrastructure may be therefore divided into three components: a) The advantages provided by the government's fiscal policy; b) The factors that make up the environment in which decisions are made; and c) The factors affecting the extent of rent-seeking activities carried out by the Government itself. (Romer, 2012)

Olson (1996) showed the importance of social infrastructure through the experiences of Germany and Korea (which represent a natural laboratory experience). After World War II, Germany and Korea were each divided into two States. Although East and West Germany were the same in almost everything when divided (the level of accumulation of financial capital, human capital, culture, population, and other determinants), each of the two countries developed a different social infrastructure with a resulting combination of different institutions and policies, thus leading to vast differences in economic performance. We expect the same scenario for Korea. This experience can also be extended to Hong Kong, Taiwan and China.

The study of the social infrastructure currently faces a problem due to the lack of an optimal or comprehensive measure. Social infrastructure includes a wide range of institutions and policies ranging from the smallest clause in the tax law to the choice of the governing regime (socialist, capitalist or otherwise). This description is not scientifically acceptable; as it makes the hypothesis that social infrastructure is important in explaining income differences across countries difficult to test. It also does not give a clear indication about which are the most important institutions or policies for boosting economic growth so that poor countries may be guided in their attempt to raise their incomes.

Actually, many research papers have tried to overcome this obstacle by listing specific important features of social infrastructure such as securing property rights, political stability, market orientation and absence of corruption. In this context, the studies of Knack and Keefer (1995) \& Mauro (1995) considered corruption not only as one of the main features shaping the social infrastructure of any country, but also a critical factor affecting other key features of social infrastructure.

On the other hand, although most empirical studies have emphasized the large negative impact of corruption on economic development, this subject has been highly controversial in the economic literature since the 1960s. The first view sees corruption as the essential grease and oil that is indispensable to facilitate the rotation of the production wheel of the economy, due to its ability to avoid the rigidity of administrative systems. In other words, this first view considers corruption a source of efficiency as it is able to remove distortions caused by obsolete institutions, cumbersome regulatory restrictions and ineffective State-imposed legal systems that hinder investment and disrupt growth-oriented economic decisions. Indeed, corruption is seen "like grease" for the engine of growth, especially within the framework of a powerless bureaucracy that suffers from inefficiency and mismanagement, as witnessed in many of the third world countries.

Conversely, the second view pictures corruption as the sand that hinders the movement of the development wheel. According to this opinion, if corruption is allowed to remove the administrative inertia by speeding up procedures, public officials will have an interest in creating more inertia and maintaining the slowness of administrative procedures to obtain more bribes. In this way, corruption becomes an obstacle impeding economic activities instead of encouraging them. This second opinion seems to prevail and has been proven through several applied studies including: Aidt, 2009; Wei and Zeckhauser, 1999; and Lash, 2004.

Therefore, this paper endeavors to examine the impact of corruption - as one of the problematic features of social infrastructure - on sustainable development within the framework of good governance; while taking into account the possibility that corruption may be an enhancer of economic efficiency at the country level. In other words, we need to find an answer to the question: Does the (Greasing the wheels) feature have a significant impact on sustainable development? 


\section{Literature Review}

Although studies tackling the relationship between corruption and economic growth began in the 1950s, they have greatly expanded since the mid-1990s due to the availability of new and more accurate indicators of corruption. The majority of these studies have found a negative impact of corruption on growth. Mauro (1995), the first applied analysis of this relationship across countries, shows that corruption has a negative impact on the per capita GDP growth rate. This result was later confirmed by several applied studies $\left({ }^{1}\right)$ which found evidence of a negative and linear relationship between corruption and economic growth. Although Lambsdorff (1999) emphasized this negative relationship, he concluded that it would be difficult to confirm the causal relationship between them.

Moreover, some researchers have had doubts about the strength of the empirical relationship between corruption and growth, especially when their analysis was based on cross-country longitudinal data; notwithstanding the fact that this methodology always raises serious concerns about the heterogeneity of data. Other studies have found that the effect of corruption on growth is not always significant; for instance Brunetti, Kisunko and Weder (1998) failed to discover any significant relationship between corruption and growth. However, some studies found that the significant relationship between corruption and growth tends to disappear when other control variables are included in the regression function. For example, Mo (2001), Pellegrini and Gerlagh (2004), and Pellegrini (2011) confirmed that the relationship between corruption and growth becomes insignificant after adjusting other important determinants of growth such as investment, human capital, openness, and political instability.

In a related context, more recent empirical studies show that the relationship between corruption and growth cannot be explained without taking into account the institutional framework of the State. A number of studies have found that the relationship between corruption and economic growth is not linear which indicates that the impact of corruption on growth may vary between countries according to the quality of the institutional framework. For example, Braguinsky (1996) believes that corruption plays a functional role in economic growth in competitive markets; while under totalitarian regimes, corruption thrusts its roots deeper in the socio- economic system eventually leading to its collapse and making it difficult for these countries to maintain or increase economic growth. Mendez and Sepulveda (2006) also found evidence of a non-linear relationship between corruption and growth. They concluded that corruption had a beneficial effect in countries with high degrees of political freedom, while elsewhere the impact of corruption on growth was not strong.

Aidt et al. (2008) also studied that relationship by dividing the sample of countries into two groups according to the quality of their governance. They found that in countries with high-quality and efficient institutions, corruption has a negative impact on growth, while in countries with lower-quality and inefficient institutions, corruption has no impact on economic growth. Similarly, Méon and Weill (2010) examined the crucial role of institutions in determining the relationship of corruption to growth, and provided evidence that corruption is less harmful in countries with a less effective institutional framework. This evidence, which seems in favor of the perspective that corruption is effective in helping to overcome existing institutional shortcomings, has been confirmed by other studies. Specifically, Heckelman and Powell study (2010) also showed that corruption is positively related to economic growth in countries where economic freedom is limited, but that that effect tended to decrease with the increase of economic freedom.

From another angle, some studies have criticized the use of the real GDP per capita indicator as a measure of development. They argued that development aims at achieving sustainable improvements in

(1) Knack and Keefer (1995), Mauro (1997), Tanzi (1998), Leite and Weidmann (1999), Tanzi and Davoodi (2000), Gyimah-Brempong (2002), Méon and Sekkat (2005). 
human well-being and since real GDP per capita does not reflect social welfare, it can be misleading. Therefore, these studies have been directed to research the relationship between corruption and sustainable development, whether using composite indicators or main and sub-indicators of sustainable development. Since the institutional dimension plays a crucial role in sustainable development, most of these studies have resorted to the integration of the institutional framework in their econometric models.

Regarding composite indicators, Aidt (2009) studied the impact of corruption on real wealth per capita as the most popular composite indicator of sustainable development. Using two corruption indicators on a sample of (60-80) countries taken during the period (1970-2000), he found that corruption was one of the main obstacles to sustainable development and that this result was robust. That finding was further confirmed by his other study Aidt (2011) using six indicators as alternatives to corruption (three of them based on perceptions, and the other three based on actual experience) on a sample of 110 countries for the period (1996-2007).

Venard (2013) also analyzed the relationship between institutional quality (as a synonym of governance) and the level of corruption and its impact on the average per capita real wealth. The study sample included 120 countries examined in four different years $(1998,2001,2004,2007)$ in order to cover a ten-year period. That sample was divided into two groups of countries according to the quality of their governance. The researcher concluded that both corruption and the low quality of the institutional framework have a negative effect on sustainable development, and that institutions affect sustainable development either directly or indirectly through their impact on corruption.

While Morse (2006) chose the Environmental Sustainability Index as one of the other composite indicators of sustainable development, to study its relationship to corruption, using a sample of 95 countries over three separate years. He concluded that pressure, State and impact indicators are not statistically related to corruption, while the only significant relationship existed between the response and corruption indicators. He also found that corruption limits any positive contribution of sustainability indicators towards the realization of environmental sustainability.

In the context of the main and sub-indicators, Lameira, et al. (2013) examined the impact of corruption - as an expression of the quality of governance - on a number of key and sub-variables associated with sustainable development, using a sample of 54 countries during the period (2000-2008). The study concluded that a positive relationship existed between the quality of governance and sustainable development. Moreover, the study revealed a significant correlation between high levels of good governance and internet user indicators, life expectancy, increased electricity consumption, market values of traded companies, and finally inflation rates. In addition, a number of studies measured the impact of corruption on environmental quality as represented by the level of CO2 emissions; such as the study of Zhang,et al. (2016) on Asia-Pacific Economic Cooperation (APEC) countries; Chen's study (2018) on China; and the study of Sinha (2019) on the BRIC countries and 11 other countries. All those studies agreed that corruption increased environmental degradation; although they disagreed on how such a negative impact occurred, according to the focal point of each research.

Although there were recent but few studies examining the relationship between corruption and the sustainability of development, they have given a strong impetus to further research in that domain.

\section{Study Model and Variables Description}

The present research aims at studying the impact of corruption on sustainable development within the framework of institutional quality while examining the possibility that corruption may boost economic efficiency for achieving sustainable development. This study depends on analyzing unbalanced Panel data 
for a large sample, including 122 developing and developed countries during the period (1996-2018) with a total of 2522 observations, selected from the available data obtained from the World Bank and International Transparency Organization.

This study relies on the Genuine Wealth Per Capita indicator (GWc) to express sustainable development. This indicator is considered a global measure of sustainable development by reputable researches such as Aidt (2009, 2011), Venard (2013); while the Corruption Perceptions Index (CPI) is used to express the level of corruption. As afore-mentioned in the Introduction (Section 1), the "Greasing the wheels" hypothesis does not assume that corruption is useful in all countries, but that it is only useful in countries with low institutional quality, where corruption acts as a means of speeding up complex bureaucratic procedures. Therefore, if we can prove the validity of this hypothesis, then it can be said that the relationship between corruption and sustainable development depends on the quality of the institutions and economic policies in different countries. Therefore, global governance indicators (WGI) were used to express the level of institutional quality (or "good governance").

Another reason for studying the relationship between corruption and sustainable development within the framework of good governance is that it is very difficult to obtain convincing evidence about the effects of a particular aspect of social infrastructure, as countries which tend to perform well in relation to one indicator of social infrastructure, display better results than the other countries. Thus, the regression of income across countries on a specific aspect of social infrastructure may be exposed to the problem of the omitted variable bias. The right-side variable (specific aspect) is likely to be correlated not only to income determinants other than social infrastructure, but also to other elements of social infrastructure. Therefore, other aspects of the social infrastructure have been added to the right-side variables to minimize as much as possible the omitted variable bias.

\section{Study Hypotheses:}

In view of the objective of the present study and the previous theoretical background, we base our analysis on the following hypotheses:

- $\quad \mathbf{H}_{1}$ : It is expected to find a negative impact of corruption on sustainable development in the countries of the study sample;

- $\quad \mathbf{H}_{2}$ : It is expected to find a positive impact of institutions (good governance) on sustainable development in the countries of the study sample; and

- $\quad \mathrm{H}_{3}$ : It is expected to find that corruption has a positive impact on economic efficiency within the framework of a low institutional quality.

\section{Econometric Model:}

In order to highlight the relationship between corruption and sustainable development within the framework of institutional quality, the first and second hypotheses have been tested. We then relied on the model used in the study of "Venard" (2013) to develop the general study model in the form of a linear function as shown in the following Equation (1):

$$
\mathrm{GW}_{\mathrm{C}_{\mathrm{t}}}=\mathrm{C}+\sum_{\mathrm{k}=1}^{\mathrm{k}} \beta_{\mathrm{k}} \mathrm{X}_{\mathrm{t}}^{\mathrm{k}}+\epsilon_{\mathrm{t}}
$$

Where $\left(\mathrm{GW}_{\mathrm{c}}\right)$ represents per capita genuine wealth in the time period $\mathrm{t}$ ranging from 1 to $\mathrm{n}(\mathrm{t}=1$, $2, \ldots, n) ; C$ denotes the constant variable, $\left(X^{k}\right)$ represents explanatory variables, and finally $\left(\epsilon_{\mathrm{t}}\right)$ represents the error term. Based on these variables, the empirical model is formulated to study the impact of corruption as one of the main features of social infrastructure on sustainable development. This model is designed as 
a semi-log function ${ }^{(1)}$ reflecting the assumed relationships. Institutional quality is represented by two variables Bureaucratic quality (RQ), and voice \& accountability (VA) in the quadratic formula, according to the non-linearity test. Therefore the main study model is drawn up as follows:

$$
\begin{aligned}
& \text { In } \mathrm{GW}_{\mathrm{Cit}}=\beta_{0_{\mathrm{iit}}}+\beta_{1} \mathrm{CPI}_{\mathrm{it}}+\beta_{2} \mathrm{GE}_{\mathrm{it}}+\beta_{3} \mathrm{PS}_{\mathrm{it}}+\beta_{4} \mathrm{RL}_{\mathrm{it}}+\beta_{5} \mathrm{RQ} \mathrm{it}_{\mathrm{it}}+\beta_{6} \mathrm{RQ}_{\mathrm{it}}^{2}+\beta_{7} \mathrm{VA}_{\mathrm{it}}+\beta_{8} \mathrm{VA}^{2}+ \\
& \beta_{9} \operatorname{dum}_{(2012-2017)}+\varepsilon_{\mathrm{t}} \quad \text { (2) }
\end{aligned}
$$

Where " $i$ " refers to each one of the 122 countries in the study sample, " $t$ " expresses the years of the time period (1996-2017)," InGWc" is the natural logarithm of real wealth per capita, "CPI" is the Corruption Perceptions Index, “GE" represents Government efficiency, "PS" political stability, and "RL" rule of law; "RQ" represents the quality of regulatory frameworks, and "VA" voice \& accountability. Due to the change in the methodology of calculating the Corruption Perceptions Index (CPI) in 2012, it became impossible to compare this index values since 2012 with its values in 2011 or any other previous year. Therefore, a dummy variable was added for the time period (2012-2017) in order to overcome this problem.

The genuine wealth or net-adjusted savings per capita (GWc) provides a much broader indicator of development sustainability by assessing changes in natural resources, environmental quality, and human capital, besides the traditional measure of changes in productive assets provided by net savings. Negative real savings rates implicitly indicate a decreasing total wealth; which means that the policies which led to such negative real savings rates are not sustainable; and vice versa in the case of increasing real savings rates.

It is noteworthy that the genuine Wealth Index has been built to carefully reflect the official definition of sustainable development, namely: "Preserving the right of future generations in the current wealth." However, this definition is insufficient as it does not determine the form of wealth that must be preserved. Does it point out to the natural resources in their current status or to other forms of wealth? This defect has been transferred to the real wealth indicator, as it is only concerned with the size of material wealth (accumulated within banks) and knowledge (investment in education) resulting from the current exploitation of natural resources, which must be kept for future generations. Hence it neglects the right of future generations to enjoy these natural resources in their original form, not only as wealth accumulated in banks or good education levels. In other words, this indicator is substituting the depletion of natural resources with the current improvement of human resources and bank savings. Thus, this indicator actually reflects sustainable development from a short or medium term perspective.

The Corruption Perceptions Index (CPI) is issued by the Transparency International Organization. It is measured through using opinion polls and carrying out specialized surveys covering local populations, business people, experts and specialists from all over the world, including the country being evaluated. This index reflects to what extent government officials use their public authority to exploit others and accept bribes, and to what extent transparency and accountability mechanisms are available. CPI values ranged between zero and ten until the index computing methodology was changed in 2012; whereas currently its values range between zero and one hundred. However in both cases, the index higher values indicate higher corruption levels and lower transparency levels. In order to make comparisons easier, firstly the CPI values of the period preceding the change of the index methodology (1996-2011) were converted pro-rata for compatibility with the following period. Secondly the range of the indicator was shifted by taking its supplement to reflect (zero) very low corruption and (100) very high corruption.

A major problem with this indicator is that it depends on perceptions, and there may be a gap between perceptions and reality ${ }^{(2)}$. For example in developing countries such as Egypt, we find that most

(1) The semi-logarithm form has been used to reduce the dispersion of real wealth per capita data.

(2) The results of the Aidt study (2009) showed a negative impact on perception-based corruption indicators on average per capita output, while the results of indicators based on actual experience were not significant. This indicates that there are significance differences between perception-based indicators of corruption and those based on actual experience. However both types of indicators agreed on the negative impact of corruption on sustainable development. 
citizens impute low development rates and the failure of the government to improve the quality of provided services to the spread of corruption; although that situation may be essentially due to the low institutional quality of the government whereas the emergence and spread of corruption is only a by-product of bad governance. Despite the drawbacks of these indicators, they represent the available indicators at the macroeconomic level and are widely used by the vast majority of corruption studies (Aidt, 2009).

The vector of institutional variables was quoted from the World Bank's Governance Indicators (WGI). Its values range from zero to (100) with higher values reflecting higher institutional quality and a more effective performance in managing governance; and vice versa. These indicators are the following $(\mathrm{WGI}, 2018)$ :

- Government Efficiency (GE): This indicator measures the degree of independence of the government apparatus from political pressures, its credibility and its ability to formulate and implement good economic policies, as well as the quality of government services provided.

- Political Stability and Absence of Violence (PS) This indicator measures the level of violence and terrorism that is rampant in societies, due to fragmentation and political exclusion, in addition to the possibility of revolutions or coups leading to the overthrow of governments by violent or unconstitutional means.

- Regulatory Quality (RQ): This indicator measures the government's ability to boost the private sector and develop it by formulating and implementing sound policies and regulations characterized by reduced bureaucratic procedures.

- Rule of Law (RL): This indicator measures the quality of the legal system in societies, the extent of their commitment to the application of contracts and to the protection of property rights, the quality of the police agencies, the judiciary and litigation procedures, and the extent of their independence from the executive authority, as well as the extent to which citizens trust the legal system of the State, as it is reflected in their respect and abidance by the law.

- Voice and Accountability (VA): This indicator measures the level of democracy or freedom enjoyed by citizens in different countries, in addition to the level of freedom enjoyed by the media, the press and the civil society, their independence from the executive authority and the freedom to participate in assemblies, elections, etc.

In order to test the third hypothesis, i.e. the validity of the "Greasing the wheels" hypothesis in the relationship between corruption and sustainable development, we use three different approaches deduced by Aidt (2011) from numerous previous studies:

1- Finding the marginal impact of corruption via its relationship to the quality of the institutional environment. The studies of "Meon and Sekkat (2005)", "Meon and Weill (2008)", "Aidt (2009)", "Ishola and Omoteso(2009)؛" found that the marginal impact of corruption is expected to be positive in countries with low institutional quality and vice versa. According to this methodology, an interactive variable is included in the model, through multiplying the institutions indicator by the corruption indicator, given that the impact of corruption is supposed to regularly interact with the quality of political institutions.

2- Finding the maximization level of the corruption impact function. In this regard, the studies of Mendez and Sepulveda (2006) and Aidt (2009) concluded that the beneficial effects of corruption are expected to exceed its harmful effects at the low levels of corruption; and vice versa. There are two methods for testing this hypothesis. The first method consists in using the quadratic formula of the corruption variable. However, this method is considered somewhat inappropriate since the corruption indicator expresses an ordinal ranking and is not a cardinal value measured on a scale. The second method depends on the classification of the sample countries according to their level of corruption. Although this second method overcomes the problem of the quadratic formula, its main disadvantage is that the classification of the sample countries is subject to value judgment, i.e., to an arbitrary choice. 
Therefore in order to eliminate this bias and classify the sample countries on an objective basis, we calculated the mean and median values of the corruption indicators of the sample countries; then we classified these countries according to the lower and higher quarter values. The lower quarter values denote low corruption countries, whereas the higher quarter values indicate high corruption countries; while the rest of the countries falling between the lower and the higher quarter values represent the group of middle corruption countries.

3- $\quad$ Finding the impact of corruption according to the quality of the political system. This approach was adopted by the studies of "Mendez and Sepulveda (2006)", "Aidt et al (2008)", "Aidt (2009)", "Venard (2013)". Under this approach, the countries of the study sample are classified according to the quality of their political institutions. The results show that the impact of corruption on sustainable development is expected to be negative in countries with high quality governance, and positive or less negative in low quality governance countries. Under this third approach, countries are also classified into high, middle and low governance countries, using the same above-mentioned procedure.

The present study tested the "Greasing the wheels" hypothesis by combining the three above-mentioned approaches in order to obtain robust results. Moreover, the sample countries were divided into three groups "high, medium and low governance countries". Thus, the present study has an edge over the previous studies which relied on only one testing methodology, while dividing the sample countries into only two categories: "High and low governance" countries. Another unique feature of the present paper is the application of these methodologies to the impact of corruption on sustainable development, while all former studies were only concerned with the impact of corruption on economic growth. Tables (1) and (2) show the descriptive statistics and the correlation matrix of the study variables, respectively.

Table 1: Descriptive Statistics of the Variables:

\begin{tabular}{|c|c|c|c|c|c|}
\hline & \multicolumn{5}{|c|}{ Total Sample } \\
\hline & Obs. & Mean & Std. Dev. & Min & Max \\
\hline GWc & 2522 & 1517 & 3251 & -2813 & 35707 \\
\hline CPI & 2334 & 54.59 & 21.85 & 0 & 96 \\
\hline $\mathrm{GE}$ & 2318 & 55.04 & 26.81 & 0.962 & 100 \\
\hline PS & 2318 & 47.14 & 27.17 & 0.474 & 100 \\
\hline $\mathrm{RL}$ & 2318 & 52.17 & 28.03 & 0.469 & 100 \\
\hline $\mathrm{RQ}$ & 2318 & 55.99 & 26.12 & 2.174 & 100 \\
\hline VA & 2318 & 52.34 & 27.39 & 2.347 & 100 \\
\hline
\end{tabular}

\begin{tabular}{ccccccc}
\hline $\begin{array}{c}\text { (Low } \\
\text { Corr.) }\end{array}$ & $\begin{array}{c}\text { (Moderate } \\
\text { Corr.) }\end{array}$ & $\begin{array}{c}\text { (High } \\
\text { Corr.) }\end{array}$ & & $\begin{array}{c}\text { (High } \\
\text { WGI) }\end{array}$ & $\begin{array}{c}\text { (Moderate } \\
\text { WGI) }\end{array}$ & $\begin{array}{c}\text { (Low } \\
\text { WGI) }\end{array}$ \\
\cline { 1 - 5 } \cline { 5 - 7 } Mean & Mean & Mean & & Mean & Mean & Mean \\
\hline 4384 & 691.1 & 156.1 & & 4420 & 751.9 & 190.3 \\
\hline 24.47 & 61.74 & 75.91 & & 25.38 & 60.93 & 75.10 \\
\hline 87.79 & 52.21 & 24.04 & & 89.48 & 53.97 & 23.82 \\
\hline 76.75 & 42.67 & 24.22 & & 80.44 & 42.74 & 23.86 \\
\hline 87.61 & 48.91 & 20.09 & & 89.76 & 50.52 & 19.06 \\
\hline 85.94 & 53.74 & 28.03 & 89.23 & 54.42 & 26.89 \\
\hline 81.55 & 48.85 & 27.38 & 87.58 & 48.21 & 26.35 \\
\hline
\end{tabular}

Table (1) underscores the large disparity between the sample countries whether regarding the countries' level of corruption, per capita wealth or governance quality; this is clearly reflected in the big difference between the minimum and maximum values of these variables. We also note that some countries have reached the maximum value of the five variables representing high quality governance; such as Denmark, Luxembourg, Norway and Finland. But no country has reached the maximum value of the corruption variables, which is logical for otherwise, it would not be called a country. What is surprising is that Denmark reached the maximum value of transparency and zero corruption in the years 1998 and 1999, as well as Finland in 2000. Of course corruption exists in all societies but in varying degrees. It cannot be totally eliminated no matter how distinguished are the levels of income, culture and institutional environment, etc. Corruption can only be reduced to a minimum value with the great improvement of these factors. Otherwise, we would have reached the concept of "The virtuous City". Therefore, obtaining a zero corruption figure may be due to the method used for calculating the CPI which is based on perceptions that may differ from reality.

As afore-mentioned, countries achieving good scores on one indicator of social infrastructure tend to display good results on the other indicators. This becomes obvious when we compare the average values of the study indicators for the groups of countries classified according to the level of corruption or governance 
quality. Hence, by examining the countries classified according to the level of corruption, we note that low corruption countries score high on good governance indicators, in addition to achieving high wealth per capita. As the level of corruption increases, the levels of wealth per capita and of good governance tend to decrease; so that the highest corruption countries have the lowest levels of good governance and sustainable development. We obtain the same result when comparing the averages of the study indicators for the groups of countries classified according to their level of good governance.

Despite this observed positive relationship between the performance of the sample countries on the social infrastructure and the sustainable development indicators, we cannot confirm whether it is the decrease in corruption that leads to the increase of the levels of institutional quality and sustainable development, or the increase of the institutional quality that leads to a decrease in corruption and an increase in sustainable development.

From Table (2), it appears that the signs of all the correlation coefficients are consistent with the economic theory and the expected relationships. Thus we find a negative correlation between corruption and sustainable development and between corruption and all the indicators of good governance. On the other hand, we find a positive relationship between all the variables representing institutional quality and sustainable development and among the various institutional variables. Finally, the corruption indicator - among the other indicators - has the highest correlation to the level of sustainable development. This result gives support to the perception of corruption as one of the main features of the institutional environment regarding its impact on the level of development.

Table 2: Correlation Matrix between Variables in Total Sample:

\begin{tabular}{|c|c|c|c|c|c|c|}
\hline & GWc & CPI & GE & PS & $\mathbf{R L}$ & RQ VA \\
\hline GWc & 1 & & & & & \\
\hline CPI & -0.618 & 1 & & & & \\
\hline $\mathrm{GE}$ & 0.522 & -0.892 & 1 & & & \\
\hline PS & 0.494 & -0.778 & 0.739 & 1 & & \\
\hline $\mathrm{RL}$ & 0.539 & -0.911 & 0.948 & 0.779 & 1 & \\
\hline RQ & 0.502 & -0.849 & 0.922 & 0.708 & 0.913 & 1 \\
\hline VA & 0.415 & -0.782 & 0.792 & 0.708 & 0.818 & 0.805 \\
\hline
\end{tabular}

Note: All Correlation Coefficient significance at $1 \%$.

\section{Econometric Analysis}

Given that the countries of the study sample are widely different in terms of sustainable development, corruption and governance levels, the econometric analysis may be affected by the disparate data of individual effects countries. This has been confirmed by the application of the "Robust test for differing group intercepts" of which the results are shown hereunder in Table (3). We notice that the calculated value of " $F$ " is significant at $1 \%$ in all the regression, leading to the rejection of the null hypothesis stating that all countries have the same intercept; and to the acceptance of the alternative hypothesis stating that the sample countries do not have the same intercept. This means that each country has its own individual effect. Therefore, the present study applied two different methodologies namely the "Fixed Effect Model" (FEM) and the "Dynamic Panel Data" (DPD) Model, to ensure the stability and robustness of the results.

The Fixed Effect Model, or the so-called OLS using dummy variables (LSDV) was selected according to the "Hausman" test which compares between the Fixed Effect Model and the Random Effect Model. According to the results of the two following tests "Residual variance" and (Breusch-Pagan), the calculated value of $\mathrm{F}$ is significant at $1 \%$, indicating that our preference should be given to the Fixed Effect Model or the Random Effect Model instead of the pooled OLS Model. However, " $F$ " calculated according to "Hausman" test is also significant, leading to our preference for the Fixed Effect Model over the Random Effect Model.

In order to take into account individual effects, dummy variables are added to the equation of each country in the Fixed Effect Model as follows: $y_{i t}=\beta_{0 i}+\beta x_{i t}+u_{i t}$

where " $i$ " refers to the $y$-intercept which differs according to the specific characteristics of each country, such as the level of culture, human capital, colonial history, religion, etc. In this way, we take into con- 
sideration in our analysis the specific features of each country while assuming that the slope coefficients of all the countries are fixed. The concept of "fixed effects" can be explained by the following statement: "Although y intercept is different in observations, it does not differ according to time and so it is timely fixed"(Gujarati, 2003).

In the Dynamic Panel Data Model, attributed to "Arellano \& Bond" (AB), the lagged dependent variable is used as an explanatory variable; thus allowing for the formulation of a partially modified dynamic model, as shown in the following equation:

$$
y_{i t}=\alpha y_{i t-1}+\hat{\beta} x_{i t}+u_{i}+\varepsilon_{i t}
$$

This model aims at removing the individual effects by taking the first-order difference equation, as in the following equation:

$$
\Delta \mathrm{y}_{\mathrm{it}}=\alpha \Delta \mathrm{y}_{\mathrm{it}-1}+\hat{\beta} \Delta \mathrm{x}_{\mathrm{it}}+\Delta \varepsilon_{\mathrm{it}}
$$

In equation (5), the compound error term is auto-correlated and is also closely correlated to the lagged dependent variable, which is a "first order moving average" $M A(1)$ including first $y_{i t-1}$ and last $\varepsilon_{\mathrm{i},-1-1}$ ' This result violates the strict external hypothesis, where an internal problem may occur, which can be solved by using endogenous instrumental variables. This method is based on lagged instrumental variables that may all be associated with $u_{i}$ of unobserved individual effects. Here, the first-order difference equation $u_{i}$ and the problem of the omitted variable bias have been removed.

Thus, the "AB" model with its extension to the GMM system is an estimator designed for the following situations: (1) ( $T$ is Small, $N$ is large), i.e., when dealing with short periods of time and a large number of individual units; (2) In the case of a linear function relationship; (3) When the dependent variable is dynamic based on the above-mentioned perception; (4) When the independent variables are not entirely external but are instead correlated to the past and present perceived error; (5) The presence of individual fixed effects, which means the absence of unobserved homogeneity, (6) The presence of heteroscedasticity and autocorrelation problems within individual unit errors, but not among these units (Baum and Christopher, 2006). The application of these two methods is an important contribution of this paper, as most studies examining the relationship between corruption and sustainable development did not take into account the individual differences between countries.

Before estimating the regressions, the researcher must ensure that all the variables are stationary at the level as the necessary prerequisite for using these two methods: (FEM and DPD). In order to verify this condition, the unit root test was applied. As shown in Fuller (1976), the unit root test does not necessarily give robust results. Therefore, the present study used four tests to ensure the robustness of its results, namely the tests of: Levin, Lin \&Chut; Im, Pesaran and Shin; ADF - Fisher; and PP - Fisher; for these tests are the most commonly used methods in applied research to detect stationary variables. The results of these tests are displayed in Table (3).

Table (3) shows that all the variables are stationary at the level at the intercept only; meaning that the variables of the model are stationary at the I(0) order. This result clearly supports the two methods applied in this study.

\section{Table (3): Panel Unit Root Test Results}

\begin{tabular}{|c|c|c|c|c|}
\hline Variable & $\begin{array}{l}\text { Levin, Lin } \\
\text { \& Chut }\end{array}$ & $\begin{array}{l}\text { Lm, Pesa- } \\
\text { ran \& Shin }\end{array}$ & $\begin{array}{l}\text { ADF - } \\
\text { Fisher }\end{array}$ & PP - Fisher \\
\hline \multirow{2}{*}{ In GWc } & -8.3666 & -6.8153 & 574.05 & 480.87 \\
\hline & $(0.000)^{* * *}$ & $(0.000)^{* * *}$ & $(0.000)^{* * *}$ & $(0.000)^{* * *}$ \\
\hline \multirow{2}{*}{ CPI } & -3.6182 & -2.6179 & 327.01 & 318.09 \\
\hline & $(0.000)^{* * *}$ & $(0.010)^{* *}$ & $(0.000)^{* * *}$ & $(0.001)^{* * *}$ \\
\hline \multirow{2}{*}{ GE } & -8.7358 & -5.9222 & 414.70 & 424.99 \\
\hline & $(0.000)^{* * *}$ & $(0.000)^{* * *}$ & $(0.000)^{* * *}$ & $(0.000)^{* * *}$ \\
\hline \multirow{2}{*}{ PS } & -11.553 & -8.9192 & 479.28 & 516.07 \\
\hline & $(0.000)^{* * *}$ & $(0.000)^{* * *}$ & $(0.000)^{* * *}$ & $(0.000)^{* * *}$ \\
\hline \multirow{2}{*}{$\mathbf{R L}$} & -9.1151 & -4.4485 & 370.88 & 379.91 \\
\hline & $(0.000)^{* * *}$ & $(0.000)^{* * *}$ & $(0.000)^{* * *}$ & $(0.000)^{* * *}$ \\
\hline \multirow{2}{*}{ RQ } & -8.3461 & -4.6196 & 351.25 & 345.80 \\
\hline & $(0.000)^{* * *}$ & $(0.000)^{* * *}$ & $(0.000)^{* * *}$ & $(0.000)^{* * *}$ \\
\hline \multirow{2}{*}{ VA } & -8.6230 & -6.6689 & 418.76 & 408.37 \\
\hline & $(0.000)^{* * *}$ & $(0.000)^{* * *}$ & $(0.000)^{* * *}$ & $(0.000)^{* * *}$ \\
\hline
\end{tabular}
(In Intercept Only): 
It is also important to ensure that the applied regressions are free from econometric problems, in order to obtain reliable results. In this regard, the various diagnostic tests indicated that the study regressions suffer from problems of heteroscedasticity, serial correlation and residual non-normality. These are all expected problems due to the large study sample of heterogeneous countries. According to the statistical theory, OLS estimators generally tend to be normally distributed with a large sample size; therefore the problem of non-normal distribution does not have a great importance here. Consequently, in the case of large samples as in our study, statistical inference will follow the OLS method of assumed normal distribution.

To overcome the two remaining problems, (FEM) was estimated using the "White cross-section standard errors", in addition to the "Firm GLS weights" robustness orders as they are both effective in eliminating the problems of heteroscedasticity and serial correlation of residuals. Although (DPD) is designed to deal with these two problems within the individual units errors as afore-mentioned, the model was estimated using an (asymptotic standard errors) robustness order. Consequently, the estimators resulting from the two measurement methods used in this study are highly dependable and efficient. Tables (4) and (4-continued) show the analysis results using the "one way FEM" (where dummy variables are added to the different countries, but not to time), as follows:

\section{Table (4): The Relationship between the CPI Index and the Genuine Wealth Per Capita:}

Dependent Variable: logarithm genuine wealth per capita (In GWc)

Method: 1-way fixed effects with (robust standard error \& cross GLS weights)

\begin{tabular}{|c|c|c|c|c|c|c|}
\hline & $\operatorname{Reg}(1 a)$ & $\operatorname{Reg}(2 a)$ & $\operatorname{Reg}(3 a)$ & $\operatorname{Reg}(4 a)$ & $\operatorname{Reg}(5 a)$ & $\operatorname{Reg}(6 a)$ \\
\hline CPI & $\begin{array}{c}-0.0199 \\
(-8.454)^{* * *}\end{array}$ & $\begin{array}{c}-0.0301 \\
(-4.329) * * *\end{array}$ & $\begin{array}{c}-0.0309 \\
(-9.294)^{* * *}\end{array}$ & $\begin{array}{c}-0.0263 \\
(-3.994)^{* * *}\end{array}$ & $\begin{array}{c}-0.0320 \\
(-5.204)^{* * *}\end{array}$ & $\begin{array}{c}-0.0133 \\
(-2.435)^{* *}\end{array}$ \\
\hline $\mathrm{CPI} * \mathrm{GE}$ & & $\begin{array}{c}0.0001 \\
(1.689)^{*}\end{array}$ & & & & \\
\hline CPI * PS & & & $\begin{array}{c}0.0002 \\
(3.999)^{* * *}\end{array}$ & & & \\
\hline $\mathrm{CPI} * \mathrm{RL}$ & & & & $\begin{array}{c}8.75 e-5 \\
(1.001)\end{array}$ & & \\
\hline $\mathrm{CPI} * \mathrm{RQ}$ & & & & & $\begin{array}{c}0.0002 \\
(2.175)^{* *}\end{array}$ & \\
\hline $\mathrm{CPI} * \mathrm{VA}$ & & & & & & $\begin{array}{l}-0.0001 \\
(-1.389)\end{array}$ \\
\hline GE & $\begin{array}{c}0.0054 \\
(1.646)^{*}\end{array}$ & $\begin{array}{l}-0.0035 \\
(-0.644)\end{array}$ & $\begin{array}{r}0.0042 \\
(1.325) \\
\end{array}$ & $\begin{array}{r}0.0050 \\
(1.565) \\
\end{array}$ & $\begin{array}{r}0.0048 \\
(1.504) \\
\end{array}$ & $\begin{array}{c}0.0058 \\
(1.825)^{*}\end{array}$ \\
\hline PS & $\begin{array}{c}0.0047 \\
(2.791)^{* * *}\end{array}$ & $\begin{array}{c}0.0045 \\
(2.715)^{* * *}\end{array}$ & $\begin{array}{l}-0.0046 \\
(-1.844)^{*}\end{array}$ & $\begin{array}{c}0.0046 \\
(2.767)^{* * *}\end{array}$ & $\begin{array}{c}0.0045 \\
(2.713)^{* * *}\end{array}$ & $\begin{array}{c}0.0049 \\
(3.021)^{* * *}\end{array}$ \\
\hline $\mathrm{RL}$ & $\begin{array}{c}0.0079 \\
(2.240)^{* *}\end{array}$ & $\begin{array}{c}0.0076 \\
(2.099)^{* *}\end{array}$ & $\begin{array}{c}0.0077 \\
(2.158)^{* *} \\
\end{array}$ & $\begin{array}{r}0.0025 \\
(0.343) \\
\end{array}$ & $\begin{array}{c}0.0080 \\
(2.307)^{* *}\end{array}$ & $\begin{array}{c}0.0078 \\
(2.154)^{* *}\end{array}$ \\
\hline RQ & $\begin{array}{c}-0.0108 \\
(-2.374)^{* *}\end{array}$ & $\begin{array}{c}-0.0125 \\
(-2.666)^{* * *}\end{array}$ & $\begin{array}{c}-0.0117 \\
(-2.574)^{* *}\end{array}$ & $\begin{array}{c}-0.0119 \\
(-2.456)^{* *}\end{array}$ & $\begin{array}{c}-0.0266 \\
(-2.798)^{* * *}\end{array}$ & $\begin{array}{c}-0.0107 \\
(-2.206)^{* *}\end{array}$ \\
\hline RQ_square & $\begin{array}{c}0.0002 \\
(4.798)^{* * *}\end{array}$ & $\begin{array}{c}0.0002 \\
(4.866)^{* * *}\end{array}$ & $\begin{array}{c}0.0002 \\
(4.930)^{* * *}\end{array}$ & $\begin{array}{c}0.0002 \\
(4.577)^{* * *}\end{array}$ & $\begin{array}{c}0.0002 \\
(4.443)^{* * *}\end{array}$ & $\begin{array}{c}0.0002 \\
(4.543)^{* * *}\end{array}$ \\
\hline VA & $\begin{array}{c}-0.0525 \\
(-6.752)^{* * *}\end{array}$ & $\begin{array}{c}-0.0535 \\
(-6.976)^{* * *}\end{array}$ & $\begin{array}{c}-0.0545 \\
(-6.532)^{* * *}\end{array}$ & $\begin{array}{c}-0.0534 \\
(-6.900)^{* * *}\end{array}$ & $\begin{array}{c}-0.0543 \\
(-7.219)^{* * *}\end{array}$ & $\begin{array}{c}-0.0433 \\
(-4.258)^{* * *}\end{array}$ \\
\hline VA_square & $\begin{array}{c}0.0004 \\
(6.896)^{* * *}\end{array}$ & $\begin{array}{c}0.0004 \\
(7.095)^{* * *}\end{array}$ & $\begin{array}{c}0.0004 \\
(6.768)^{* * *}\end{array}$ & $\begin{array}{c}0.0004 \\
(6.850)^{* * *}\end{array}$ & $\begin{array}{c}0.0004 \\
(7.141)^{* * *}\end{array}$ & $\begin{array}{c}0.0004 \\
(5.239)^{* * *}\end{array}$ \\
\hline dummy (2012-2017) & $\begin{array}{c}0.2038 \\
(3.878)^{* * *}\end{array}$ & $\begin{array}{c}0.1905 \\
(3.414)^{* * *}\end{array}$ & $\begin{array}{c}0.1813 \\
(3.465)^{* * *}\end{array}$ & $\begin{array}{c}0.1969 \\
(3.538)^{* * *}\end{array}$ & $\begin{array}{c}0.1886 \\
(3.352)^{* * *}\end{array}$ & $\begin{array}{c}0.2110 \\
(3.922)^{* * *}\end{array}$ \\
\hline Cons & $\begin{array}{c}7.7592 \\
(27.27)^{* * *}\end{array}$ & $\begin{array}{c}8.5075 \\
(17.30)^{* * *}\end{array}$ & $\begin{array}{c}8.6063 \\
(26.63)^{* * *}\end{array}$ & $\begin{array}{c}8.2468 \\
(16.61)^{* * *}\end{array}$ & $\begin{array}{c}8.7132 \\
(16.84)^{* * *}\end{array}$ & $\begin{array}{c}7.2670 \\
(17.17)^{* * *}\end{array}$ \\
\hline$\overline{\mathbf{R}}^{2}$ & $\% 93.3$ & $\% 93.3$ & $\% 93.4$ & $\% 93.3$ & $\% 93.3$ & \%93.2 \\
\hline Fisher test (F-stat.) & {$[207.6]^{* * *}$} & {$[206.9]^{* * *}$} & {$[209.7]^{* * *}$} & {$[205.2]^{* * *}$} & {$[206.9]^{* * *}$} & {$[203.9]^{* * *}$} \\
\hline
\end{tabular}




\begin{tabular}{|c|c|c|c|c|c|c|}
\hline & $\operatorname{Reg}(1 a)$ & $\operatorname{Reg}(2 a)$ & $\operatorname{Reg}(3 a)$ & $\operatorname{Reg}(4 a)$ & $\operatorname{Reg}(5 a)$ & $\operatorname{Reg}(6 a)$ \\
\hline Countries & 122 & 122 & 122 & 122 & 122 & 122 \\
\hline \multirow[t]{2}{*}{ Obs. } & 2038 & 2038 & 2038 & 2038 & 2038 & 2038 \\
\hline & \multicolumn{6}{|c|}{ Effects Specification tests } \\
\hline Robust test & {$[79.18]^{* * *}$} & {$[78.28]^{* * *}$} & {$[78.83]^{* * *}$} & {$[79.96]^{* * *}$} & {$[77.86]^{* * *}$} & {$[75.50]^{* * *}$} \\
\hline Residual variance test & {$[19.98]^{* * *}$} & {$[19.97]^{* * *}$} & {$[20.01]^{* * *}$} & {$[19.97]^{* * *}$} & {$[19.94]^{* * *}$} & {$[19.87]^{* * *}$} \\
\hline Breusch-Pagan test & {$[3958]^{* * *}$} & {$[3960]^{* * *}$} & {$[3959]^{* * *}$} & {$[3958]^{* * *}$} & {$[3948]^{* * *}$} & {$[3902]^{* * *}$} \\
\hline Hausman test & {$[20.53]^{* *}$} & {$[20.73]^{* *}$} & {$[21.44]^{* *}$} & {$[20.38]^{* * *}$} & {$[20.61]^{* *}$} & {$[21.07]^{* *}$} \\
\hline Time test & {$[154.8]^{* * *}$} & {$[149.9]^{* * *}$} & {$[151.2]^{* * *}$} & {$[153.5]^{* * *}$} & {$[154.9]^{* * *}$} & {$[155.3]^{* * *}$} \\
\hline
\end{tabular}

Note: $-* * *, * *, *$ indicate significance at $1 \%, 5 \%$ and $10 \%$ respectively.

\section{Table (4) - Continuous: The Relationship between the CPI Index and the Genuine Wealth Per capita:}

Dependent Variable: logarithm genuine wealth per capita (ln GWc)

Method: 1-way fixed effects with (robust standard error \& cross GLS weights)

\begin{tabular}{|c|c|c|c|c|c|c|c|}
\hline & $\operatorname{Reg}(7 a)$ & $\operatorname{Reg}(8 a)$ & $\operatorname{Reg}(9 a)$ & $\operatorname{Reg}(10 a)$ & $\operatorname{Reg}(11 a)$ & $\operatorname{Reg}(12 a)$ & $\operatorname{Reg}(13 a)$ \\
\hline & $\begin{array}{c}\text { (Total Sam- } \\
\text { ple) }\end{array}$ & (Low Corr.) & $\begin{array}{c}\text { (Moderate } \\
\text { Corr.) }\end{array}$ & (High Corr.) & (High WGI) & $\begin{array}{c}\text { (Moderate } \\
\text { WGI) }\end{array}$ & (Low WGI) \\
\hline $\mathrm{CPI}$ & $\begin{array}{c}0.0184 \\
(4.610)^{* * *}\end{array}$ & $\begin{array}{l}-0.0029 \\
(-1.272)\end{array}$ & $\begin{array}{c}-0.0252 \\
(-4.973) * * *\end{array}$ & $\begin{array}{c}-0.0450 \\
(-5.591) * * *\end{array}$ & $\begin{array}{c}-0.0066 \\
(-1.805)^{*}\end{array}$ & $\begin{array}{c}-0.0313 \\
(-8.090) * * *\end{array}$ & $\begin{array}{c}-0.0156 \\
(-1.936)^{*}\end{array}$ \\
\hline CPI_square & $\begin{array}{c}-0.0004 \\
(-8.531)^{* * *}\end{array}$ & & & & & & \\
\hline $\mathrm{GE}$ & $\begin{array}{r}0.0037 \\
(1.196)\end{array}$ & $\begin{array}{c}0.0116 \\
(2.009)^{* *}\end{array}$ & $\begin{array}{l}-0.0016 \\
(-0.364)\end{array}$ & $\begin{array}{c}0.0111 \\
(2.725)^{* * *}\end{array}$ & $\begin{array}{l}-0.0015 \\
(-0.252)\end{array}$ & $\begin{array}{r}0.0027 \\
(0.594)\end{array}$ & $\begin{array}{c}0.0132 \\
(3.167)^{* * *}\end{array}$ \\
\hline PS & $\begin{array}{c}0.0040 \\
(2.367)^{* *} \\
\end{array}$ & $\begin{array}{l}-0.0005 \\
(-0.187) \\
\end{array}$ & $\begin{array}{c}0.0062 \\
(2.652)^{* * *}\end{array}$ & $\begin{array}{r}0.0013 \\
(0.382) \\
\end{array}$ & $\begin{array}{c}-0.0061 \\
(-2.495)^{* *}\end{array}$ & $\begin{array}{c}0.0087 \\
(4.513)^{* * *}\end{array}$ & $\begin{array}{c}0.0072 \\
(2.007)^{* *}\end{array}$ \\
\hline $\mathrm{RL}$ & $\begin{array}{c}0.0081 \\
(2.358)^{* *}\end{array}$ & $\begin{array}{c}0.0228 \\
(3.707)^{* * *}\end{array}$ & $\begin{array}{c}0.0172 \\
(3.622)^{* * *}\end{array}$ & $\begin{array}{l}-0.0038 \\
(-0.713)\end{array}$ & $\begin{array}{c}0.0313 \\
(3.574)^{* * *}\end{array}$ & $\begin{array}{r}0.0034 \\
(0.930)\end{array}$ & $\begin{array}{r}0.0047 \\
(0.701) \\
\end{array}$ \\
\hline RQ & $\begin{array}{c}-0.0123 \\
(-2.733)^{* * *}\end{array}$ & $\begin{array}{c}0.0093 \\
(1.238)\end{array}$ & $\begin{array}{r}0.0009 \\
(0.303)\end{array}$ & $\begin{array}{r}0.0059 \\
(1.461)\end{array}$ & $\begin{array}{c}0.0115 \\
(1.774)^{*}\end{array}$ & $\begin{array}{r}0.0041 \\
(1.133)\end{array}$ & $\begin{array}{r}0.0029 \\
(0.693)\end{array}$ \\
\hline RQ_square & $\begin{array}{c}0.0002 \\
(5.484)^{* * *}\end{array}$ & & & & & & \\
\hline VA & $\begin{array}{c}-0.0542 \\
(-6.763)^{* * *}\end{array}$ & $\begin{array}{c}0.0137 \\
(3.935)^{* * *} \\
\end{array}$ & $\begin{array}{c}-0.0618 \\
(-8.416)^{* * *}\end{array}$ & $\begin{array}{c}-0.0258 \\
(-3.009) * * *\end{array}$ & $\begin{array}{c}0.0120 \\
(2.326)^{* *}\end{array}$ & $\begin{array}{c}-0.0484 \\
(-5.100)^{* * *}\end{array}$ & $\begin{array}{c}-0.0294 \\
(-3.582)^{* * *}\end{array}$ \\
\hline VA_square & $\begin{array}{c}0.0004 \\
(6.783)^{* * *}\end{array}$ & & $\begin{array}{c}0.0004 \\
(4.037)^{* * *}\end{array}$ & & & $\begin{array}{c}0.0003 \\
(3.264)^{* * *}\end{array}$ & \\
\hline dummy (2012-2017) & $\begin{array}{c}0.1372 \\
(2.538)^{* *}\end{array}$ & $\begin{array}{c}0.1671 \\
(3.199)^{* * *}\end{array}$ & $\begin{array}{c}0.1277 \\
(1.926)^{*}\end{array}$ & $\begin{array}{c}0.2455 \\
(2.874)^{* * *}\end{array}$ & $\begin{array}{c}0.1611 \\
(3.062)^{* * *}\end{array}$ & $\begin{array}{c}0.1540 \\
(2.438)^{* *}\end{array}$ & $\begin{array}{c}0.3295 \\
(3.575)^{* * *}\end{array}$ \\
\hline Cons & $\begin{array}{c}7.2688 \\
(28.35)^{* * *}\end{array}$ & $\begin{array}{c}3.1269 \\
(5.257)^{* * *}\end{array}$ & $\begin{array}{c}8.4539 \\
(18.42)^{* * *}\end{array}$ & $\begin{array}{c}8.8016 \\
(13.54)^{* * *}\end{array}$ & $\begin{array}{c}3.7256 \\
(5.896)^{* * *}\end{array}$ & $\begin{array}{c}8.4682 \\
(22.49)^{* * *}\end{array}$ & $\begin{array}{c}6.2540 \\
(9.271)^{* * *}\end{array}$ \\
\hline$\overline{\mathbf{R}}^{2}$ & $\% 93.6$ & $\% 86.3$ & $\% 91$ & $\% 77.2$ & $\% 87$ & $\% 91.6$ & $\% 77.7$ \\
\hline Fisher test (F-stat.) & {$[217.7]^{* * *}$} & {$[84.04]^{* * *}$} & {$[145.2]^{* * *}$} & {$[43.11]^{* * *}$} & {$[86.36]^{* * *}$} & {$[155.2]^{* * *}$} & {$[46.59]^{* * *}$} \\
\hline Countries & 122 & 32 & 60 & 30 & 29 & 61 & 31 \\
\hline Obs. & 2038 & 554 & 998 & 486 & 512 & 1021 & 486 \\
\hline & \multicolumn{7}{|c|}{ Effects Specification tests } \\
\hline Robust test & {$[76.55]^{* * *}$} & {$[51.25]^{* * *}$} & {$[76.88]^{* * *}$} & {$[38.86]^{* * *}$} & {$[22.27]^{* * *}$} & {$[73.12]^{* * *}$} & {$[42.55]^{* * *}$} \\
\hline Residual variance test & {$[20.08]^{* * *}$} & {$[36.13]^{* * *}$} & {$[22.94]^{* * *}$} & {$[23.28]^{* * *}$} & {$[8.834 * * *$} & {$[21.39]^{* * *}$} & {$[16.89]^{* * *}$} \\
\hline Breusch-Pagan test & {$[3963]^{* * *}$} & {$[1905]^{* * *}$} & {$[2061]^{* * *}$} & {$[934.9]^{* * *}$} & {$[271.8]^{* * *}$} & {$[2097]^{* * *}$} & {$[634.6]^{* * *}$} \\
\hline Hausman test & {$[22.62]^{* *}$} & {$[20.62]^{* *}$} & {$[22.42]^{* *}$} & {$[18.48]^{* *}$} & {$[19.49]^{* * *}$} & {$[30.12]^{* * *}$} & {$[18.32]^{* *}$} \\
\hline Time test & {$[135.9]^{* * *}$} & {$[271.9]^{* * *}$} & {$[117.6]^{* * *}$} & {$[83.38]^{* * *}$} & {$[195.9]^{* * *}$} & {$[107.3]^{* * *}$} & {$[132.3]^{* * *}$} \\
\hline
\end{tabular}

Note: $-* * *, * *, *$ indicate significance at $1 \%, 5 \%$ and $10 \%$ respectively.

- Singapore has been eliminated from the group of high-governance countries in the model (11a), because of the low level of the voice and accountability indicator compared to the rest of the good governance indicators, making it an anomalous value negatively affecting the results of the analysis. 

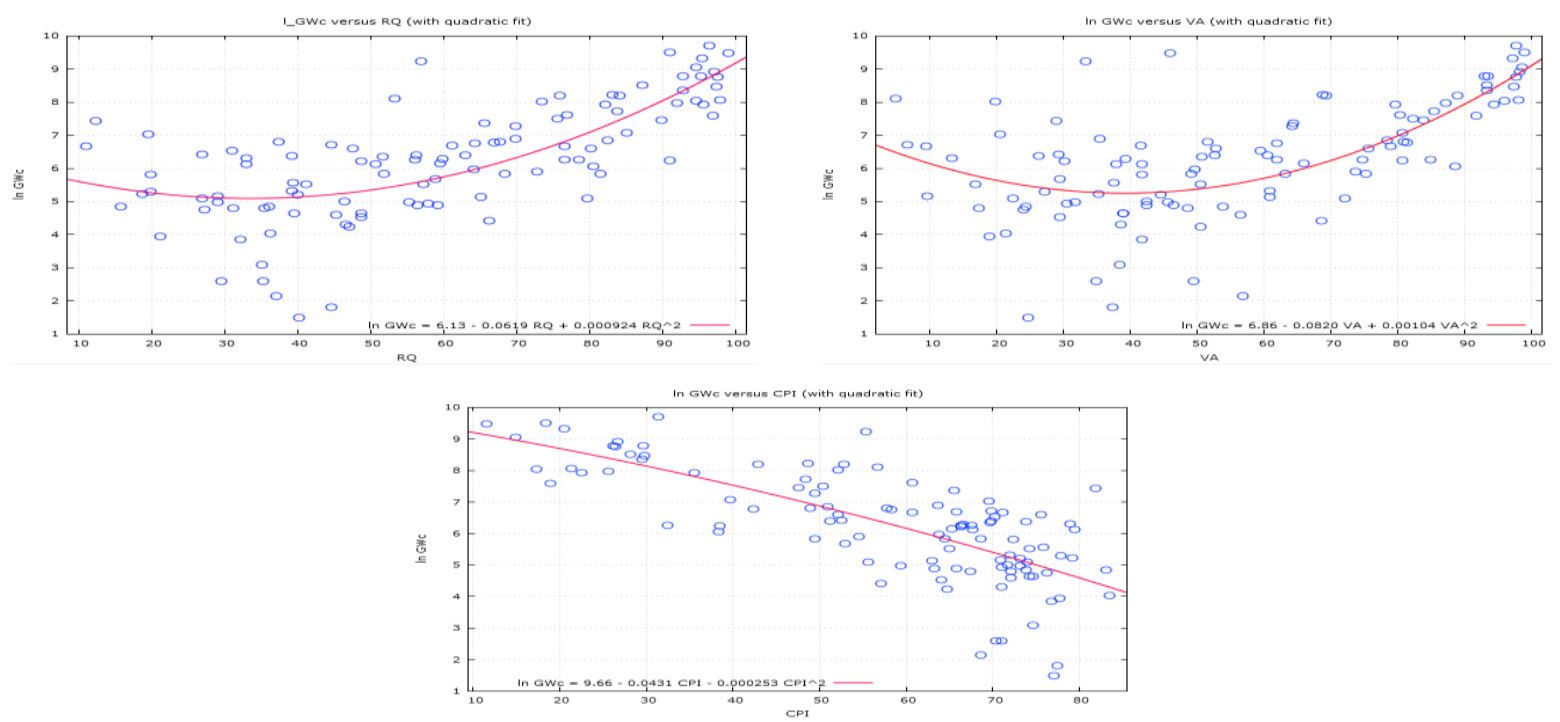

Regression (1a) displays the results of the model. We note a negative impact of corruption (CPI) on sustainable development at the level of $1 \%$; hence the increase of corruption by one degree leads to a decrease in wealth per capita equal to $\$ 0.02$ on average. This result is consistent with the studies of Aidt $(2009,2011)$ and Venard (2013) which support the first hypothesis of the present study. However, the results of the rest of the institutional variables representing the social infrastructure of the examined countries support the second hypothesis of this study; namely that institutions (good governance) have a positive impact on sustainable development but that this impact varies between a linear function and a quadratic function. The (GE), (PS) and

Table (5): Sasabuchi-Lind-Mehlum Ttest for an Inverse U-shaped Relationship:

\begin{tabular}{|c|c|c|c|c|}
\hline & & $\operatorname{Reg}(1 a)$ & $\operatorname{Reg}(1 a)$ & $\operatorname{Reg}(7 a)$ \\
\hline & & RQ & VA & CPI \\
\hline$X_{i}$ & $\widehat{\beta}=$ & $\begin{array}{c}-0.0108 \\
(-2.374)^{* *}\end{array}$ & $\begin{array}{c}-0.0525 \\
(-6.752)^{* * *}\end{array}$ & $\begin{array}{c}0.0184 \\
(4.610)^{* * *}\end{array}$ \\
\hline$X_{i}^{2}$ & $\hat{\gamma}=$ & $\begin{array}{c}0.0002 \\
(4.798)^{* * *}\end{array}$ & $\begin{array}{c}0.0004 \\
(6.896)^{* * *}\end{array}$ & $\begin{array}{c}-0.0004 \\
(-8.531)^{* * *}\end{array}$ \\
\hline \multirow[t]{2}{*}{ Interval } & $X_{1(\min )}=$ & 2.1739 & 2.3474 & 0 \\
\hline & $X_{h(\max )}=$ & 100 & 100 & 96 \\
\hline Slope at $X_{1}$ & $\widehat{\beta}+2 \hat{\gamma} \mathrm{X}_{1}=$ & $\begin{array}{c}-0.0101 \\
(-1.766)^{* *}\end{array}$ & $\begin{array}{c}-0.0507 \\
(-5.021)^{* * *}\end{array}$ & $\begin{array}{c}0.0184 \\
(1.821)^{* *}\end{array}$ \\
\hline Slope at $X_{h}$ & $\widehat{\beta}+2 \hat{\gamma} X_{h}=$ & $\begin{array}{c}0.0228 \\
(5.923)^{* * *}\end{array}$ & $\begin{array}{c}0.0247 \\
(3.298)^{* * *}\end{array}$ & $\begin{array}{c}-0.0609 \\
(-4.409) * * *\end{array}$ \\
\hline Sasabuchi test & & $\begin{array}{c}2.936 \\
(3.589)^{* * *}\end{array}$ & $\begin{array}{c}3.259 \\
(2.345)^{* * *} \\
\end{array}$ & $\begin{array}{c}1.853 \\
(0.033) \\
\end{array}$ \\
\hline Extremum Point & $-\widehat{\beta} /(2 \hat{\gamma})=$ & 32.21 & 68.07 & 22.33 \\
\hline $\begin{array}{l}90 \% \text { confidence in- } \\
\text { terval, Fieller method }\end{array}$ & & {$[25.4: 37.1]$} & {$[51.3: 72.9]$} & {$[19.5: 27.4]$} \\
\hline $\begin{array}{l}90 \% \text { confidence in- } \\
\text { terval, Dellta method }\end{array}$ & & [27.9:35.2] & [55.4: 71.0] & {$[20.1: 27.1]$} \\
\hline
\end{tabular}

Note: - ***,**,* indicate significance at $1 \%, 5 \%$ and $10 \%$ respectively. $(\mathrm{RL})$ variables have a linear impact on sustainable development. On the other hand, the (RQ) and (VA) variables have a non-linear (U-shaped) impact on sustainable development; and this impact is negative at the low levels of these two variables, but becomes positive at their highest levels.

To ascertain the existence of a (U-shaped) or an (inverted U-shaped) relationship, the test of (Sasabuchi-Lind-Mehlum) was conducted. The results in Table 4 show that the (RQ) and (VA) variables are significant at the $1 \%$ level. This finding supports the rejection of the null hypothesis that there is an inverted $\mathrm{U}$-shaped relationship and the acceptance of the alternative hypothesis or the existence of a U-shaped relationship between these two variables and sustainable development. It is also clear that the values of these two variables corresponding to the U-curve turning point are 32.2 and 68.1, respectively. This means that in 
the countries where the (RQ) and (VA) variables are greater than these values, they have a positive impact on sustainable development, and vice versa. Table 4 also shows the confidence interval of the turning point.

The results of Regression (1a) are as a whole stationary. This has been confirmed after testing the hypothesis of "Greasing the wheels" in all the sample countries using the first method; as evidenced by the regressions from (2a) to (6a). We also note that the corruption variable has the largest coefficient compared to all the other institutional variables. This finding stresses the importance of corruption as one of the most critical institutional factors shaping the social infrastructure of a country.

The first method which was proposed by Meon and Sekkat (2005) for testing the "Greasing the wheels" hypothesis was applied to the regressions (2a) to (6a). According to this method, we add an interactive variable by multiplying each institutional variable individually by the corruption variable. We notice here that the negative direct impact of corruption remains the same in all the regressions from (2a) to (6a), although the magnitude of its coefficient increases; whereas the indirect impact of corruption (interactive variable) has a positive value in the three regressions (2a), (3a) and (5a).

This result may support the validity of the "Greasing the wheels" hypothesis for describing the interaction between corruption and the (GF), (PS), and (RQ) variables. In other words, corruption can partially compensate the inefficiency and poor organization of the institutions at the country level. Besides, corruption can partially offset the impact of political instability on sustainable development. As for the two remaining regressions, the interactive variable had no effect. This means that corruption enhances economic efficiency but not via its relationship to the rule of law and the level of democracy variables. These results differ partially from the findings of Meon and Sekkat (2005), who reached systematic evidence supporting the rejection of this hypothesis. However, they used a different dependent variable.

In Table (3-Continued) the regressions (7a) to (10a) are displayed and illustrate the second approach for testing the "Greasing the wheels" hypothesis, based on maximizing the corruption impact function. The quadratic formula of corruption was included in the regression (7a) according to the first method under the above-mentioned approach. The results came similar to those of the study of Mendez and Sepulveda (2006) concerning the impact of corruption on per capita output. The impact of corruption on sustainable development takes the form of "an inverted U" curve increasing up to a maximum level then decreasing; thus indicating a positive impact at the low corruption levels and a negative impact at the high corruption levels.

This finding was confirmed by the (Sasabuchi-Lind-Mehlum) test as shown in Table (5). The result of the test was not significant, leading to the acceptance of the null hypothesis indicating an Inverted $\mathrm{U}$-shaped relationship. We also found that the curve reaches its maximum value when corruption is equal to 22.3 degrees. That is, the impact of corruption is negative on sustainable development in the countries where corruption exceeds 22.3 degrees, and such countries represent the vast majority of the sample countries. Actually only seven countries of the study sample scored an average degree of corruption below this value during the study period. These countries were: Singapore, Sweden, Canada, Norway, the United Kingdom, Switzerland and New Zealand.

Then the second method was applied to the regressions (8a), (9a) and (10a) through dividing the total sample of countries into low, medium and high corruption countries. The results were consistent with the results of the first method (quadratic formula) as we found that the corruption impact function has a maximization level. We observed that there was no impact of corruption on sustainable development in countries with low levels of corruption falling below 22.3 degrees, while the impact of corruption turns negative in the countries witnessing medium and high levels of corruption. Moreover, the negative impact of corruption increases as we move from medium to highly corrupted countries. We conclude that according to the two methods of the second approach, corruption does not enhance economic efficiency. This conclusion contradicts the results of the first approach for testing the "Greasing the wheel" hypothesis; however it supports the validity of the "sand in the wheels" hypothesis. 
The third and final method for testing the "Greasing the wheels" hypothesis was applied to the regressions (11a), (12a) and (13a) by dividing the total sample countries according to their institutions quality (good governance) into high, medium and low governance countries. The results of this method were somewhat consistent with those of both the first and second methods of the second approach. Hence we found that the negative impact of corruption increases as we move from high to medium governance countries. In low governance countries, the impact of corruption is relatively lower than that of medium governance countries (but is still higher than in high governance countries). This result is again consistent with the "Greasing the wheels" hypothesis which suggests that corruption has less effect in countries with low governance.

Although the total sample of countries has been divided into subsamples, either according to the country's level of corruption or good governance, in order to obtain more homogenous characteristics in each subsample, we notice that the regressions (9a) and (12a), representing the subsample of medium corruption countries, and the subsample of the medium good governance countries respectively, show that the relationship between the level of (VA) and sustainable development still takes the form of a U-shaped curve. This is due to the large size of these two subsamples, with many individual cases of countries having realized an impressive progress in their democracy level when compared to the low level of their other institutional variables; and vice versa.

Table (6): Robustness Analysis:

Dependent Variable: Logarithm Genuine wealth per capita ( $\ln \mathrm{GWc}$ )

Method: 2-step dynamic panel with robust standard error

\begin{tabular}{|c|c|c|c|c|c|c|}
\hline & $\operatorname{Reg}(1 b)$ & $\operatorname{Reg}(2 b)$ & $\operatorname{Reg}(3 b)$ & $\operatorname{Reg}(4 b)$ & $\operatorname{Reg}(5 b)$ & $\operatorname{Reg}(6 b)$ \\
\hline $\ln \mathrm{GWc}(-1)$ & $\begin{array}{c}0.3213 \\
(88.32)^{* * *}\end{array}$ & $\begin{array}{c}0.3220 \\
(81.76)^{* * *}\end{array}$ & $\begin{array}{c}0.3200 \\
(85.60)^{* * *}\end{array}$ & $\begin{array}{c}0.3216 \\
(87.72)^{* * *}\end{array}$ & $\begin{array}{c}0.3213 \\
(88.34)^{* * *}\end{array}$ & $\begin{array}{c}0.3249 \\
(82.29)^{* * *}\end{array}$ \\
\hline $\mathrm{CPI}$ & $\begin{array}{c}-0.0120 \\
(-8.728)^{* * *}\end{array}$ & $\begin{array}{c}-0.0135 \\
(-4.325) * * *\end{array}$ & $\begin{array}{c}-0.0160 \\
(-6.629) * * *\end{array}$ & $\begin{array}{c}-0.0142 \\
(-3.619) * * *\end{array}$ & $\begin{array}{c}-0.0117 \\
(-4.575) * * *\end{array}$ & $\begin{array}{c}-0.0276 \\
(-11.32)^{* * *} \\
\end{array}$ \\
\hline $\mathrm{CPI} * \mathrm{GE}$ & & $\begin{array}{r}1.83 e-5 \\
(0.382) \\
\end{array}$ & & & & \\
\hline $\mathrm{CPI} * \mathrm{PS}$ & & & $\begin{array}{c}6.10 \mathrm{e}-5 \\
(1.928)^{*}\end{array}$ & & & \\
\hline $\mathrm{CPI} * \mathrm{RL}$ & & & & $\begin{array}{l}3.25 \mathrm{e}-5 \\
(1.001)\end{array}$ & & \\
\hline $\mathrm{CPI} * \mathrm{RQ}$ & & & & & $\begin{array}{c}-5.13 e-6 \\
(-0.133)\end{array}$ & \\
\hline $\mathrm{CPI} * \mathrm{VA}$ & & & & & & $\begin{array}{c}0.0003 \\
(6.585)^{* * *}\end{array}$ \\
\hline $\mathrm{GE}$ & $\begin{array}{c}0.0262 \\
(15.17)^{* * *}\end{array}$ & $\begin{array}{c}0.0246 \\
(6.551)^{* * *}\end{array}$ & $\begin{array}{c}0.0260 \\
(14.32)^{* * *}\end{array}$ & $\begin{array}{c}0.0255 \\
(12.08)^{* * *}\end{array}$ & $\begin{array}{c}0.0232 \\
(15.13)^{* * *}\end{array}$ & $\begin{array}{c}0.0245 \\
(12.85)^{* * *}\end{array}$ \\
\hline PS & $\begin{array}{c}0.0017 \\
(2.623)^{* * *}\end{array}$ & $\begin{array}{c}0.0016 \\
(2.530)^{* *}\end{array}$ & $\begin{array}{l}-0.0020 \\
(-0.888)\end{array}$ & $\begin{array}{c}0.0015 \\
(2.273)^{* *}\end{array}$ & $\begin{array}{c}0.0016 \\
(2.508)^{* *}\end{array}$ & $\begin{array}{r}0.0008 \\
(1.178) \\
\end{array}$ \\
\hline $\mathrm{RL}$ & $\begin{array}{c}-0.0228 \\
(-9.741)^{* * *}\end{array}$ & $\begin{array}{c}-0.0234 \\
(-7.128)^{* * *}\end{array}$ & $\begin{array}{c}-0.0255 \\
(-9.643)^{* * *}\end{array}$ & $\begin{array}{c}-0.0265 \\
(-3.540)^{* * *}\end{array}$ & $\begin{array}{c}-0.0226 \\
(-6.325)^{* * *}\end{array}$ & $\begin{array}{c}-0.0305 \\
(-10.35)^{* * *} \\
\end{array}$ \\
\hline RL_square & $\begin{array}{c}0.0002 \\
(6.342)^{* * *}\end{array}$ & $\begin{array}{c}0.0002 \\
(4.543)^{* * *}\end{array}$ & $\begin{array}{c}0.0002 \\
(6.452)^{* * *}\end{array}$ & $\begin{array}{c}0.0002 \\
(3.939)^{* * *}\end{array}$ & $\begin{array}{c}0.0002 \\
(4.368)^{* * *}\end{array}$ & $\begin{array}{c}0.0002 \\
(8.123)^{* * *}\end{array}$ \\
\hline RQ & $\begin{array}{c}0.0034 \\
(3.807)^{* * *}\end{array}$ & $\begin{array}{c}0.0035 \\
(3.789)^{* * *}\end{array}$ & $\begin{array}{c}0.0034 \\
(3.504)^{* * *}\end{array}$ & $\begin{array}{c}0.0037 \\
(3.540)^{* * *}\end{array}$ & $\begin{array}{r}0.0037 \\
(1.572) \\
\end{array}$ & $\begin{array}{c}0.0034 \\
(3.652)^{* * *} \\
\end{array}$ \\
\hline VA & $\begin{array}{c}-0.0173 \\
(-7.211)^{* * *}\end{array}$ & $\begin{array}{c}-0.0175 \\
(-7.201)^{* * *}\end{array}$ & $\begin{array}{c}-0.0176 \\
(-7.496)^{* * *}\end{array}$ & $\begin{array}{c}-0.0178 \\
(-6.988)^{* * *}\end{array}$ & $\begin{array}{c}-0.0173 \\
(-7.128)^{* * *}\end{array}$ & $\begin{array}{c}-0.0434 \\
(-9.379)^{* * *}\end{array}$ \\
\hline VA_square & $\begin{array}{c}0.0001 \\
(4.185)^{* * *} \\
\end{array}$ & $\begin{array}{c}0.0001 \\
(4.204)^{* * *} \\
\end{array}$ & $\begin{array}{c}0.0001 \\
(4.336)^{* * *} \\
\end{array}$ & $\begin{array}{c}0.0001 \\
(4.132)^{* * *} \\
\end{array}$ & $\begin{array}{c}0.0001 \\
(4.111)^{* * *} \\
\end{array}$ & $\begin{array}{c}0.0003 \\
(6.701)^{* * *} \\
\end{array}$ \\
\hline dummy (2012-2017) & $\begin{array}{c}-0.0105 \\
(-1.844)^{*}\end{array}$ & $\begin{array}{c}-0.0134 \\
(-2.103)^{* *}\end{array}$ & $\begin{array}{c}-0.0174 \\
(-2.551)^{* *}\end{array}$ & $\begin{array}{c}-0.0136 \\
(-1.816)^{*}\end{array}$ & $\begin{array}{c}-0.0105 \\
(-1.665)^{*}\end{array}$ & $\begin{array}{c}-0.0237 \\
(-3.836)^{* * *} \\
\end{array}$ \\
\hline Cons & $\begin{array}{c}4.3092 \\
(33.34)^{* * *}\end{array}$ & $\begin{array}{c}4.4419 \\
(16.62)^{* * *}\end{array}$ & $\begin{array}{c}4.6509 \\
(21.48)^{* * *}\end{array}$ & $\begin{array}{c}4.5243 \\
(12.51)^{* * *}\end{array}$ & $\begin{array}{c}4.2913 \\
(19.54)^{* * *}\end{array}$ & $\begin{array}{c}5.7130 \\
(25.66)^{* * *}\end{array}$ \\
\hline
\end{tabular}




\begin{tabular}{|c|c|c|c|c|c|c|}
\hline & $\operatorname{Reg}(1 b)$ & $\operatorname{Reg}(2 b)$ & $\operatorname{Reg}(3 b)$ & $\operatorname{Reg}(4 b)$ & $\operatorname{Reg}(5 b)$ & $\operatorname{Reg}(6 b)$ \\
\hline Countries & 122 & 122 & 122 & 122 & 122 & 122 \\
\hline Obs. & 1977 & 1977 & 1977 & 1977 & 1977 & 1977 \\
\hline & \multicolumn{6}{|c|}{ Auxiliary test statistics } \\
\hline Number of instruments & 229 & 230 & 230 & 230 & 230 & 230 \\
\hline Test for AR(1) errors & {$[-4.882]^{* * *}$} & {$[-4.883]^{* * *}$} & {$[-4.879]^{* * *}$} & {$[-4.884]^{* * *}$} & {$[-4.882]^{* * *}$} & {$[-4.887]^{* * *}$} \\
\hline Test for $\mathrm{AR}(2)$ errors & {$[-0.014]$} & {$[-0.013]$} & {$[-0.042]$} & {$[-0.020]$} & {$[-0.013]$} & {$[-0.052]$} \\
\hline Sargan trst & {$[120.4]$} & [120.5] & [120.3] & {$[120.1]$} & {$[120.4]$} & {$[119.8]$} \\
\hline Wald (joint) test & {$[18053]^{* * *}$} & {$[17037]^{* * *}$} & {$[17899]^{* * *}$} & {$[18045]^{* * *}$} & {$[18004]^{* * *}$} & {$[16900]^{* * *}$} \\
\hline
\end{tabular}

Note: $-* * *, * *, *$ indicate significance at $1 \%, 5 \%$ and $10 \%$ respectively.

\section{Table (6) - Continuous: Robustness Analysis:}

Dependent Variable: Logarithm Genuine wealth per capita (In GWc)

Method: 2-step dynamic panel with robust standard error

\begin{tabular}{|c|c|c|c|c|c|c|c|}
\hline & $\operatorname{Reg}(7 b)$ & $\operatorname{Reg}(8 b)$ & $\operatorname{Reg}(9 b)$ & $\operatorname{Reg}(10 b)$ & $\operatorname{Reg}(11 b)$ & $\operatorname{Reg}(12 b)$ & $\operatorname{Reg}(13 b)$ \\
\hline & $\begin{array}{c}\text { (Total Sam- } \\
\text { ple) }\end{array}$ & (Low Corr.) & $\begin{array}{c}\text { (Moderate } \\
\text { Corr.) }\end{array}$ & $\begin{array}{l}\text { (High } \\
\text { Corr.) }\end{array}$ & (High WGI) & $\begin{array}{l}\text { (Moderate } \\
\text { WGI) }\end{array}$ & (Low WGI) \\
\hline $\ln$ GWc $(-1)$ & $\begin{array}{c}0.3211 \\
(83.78)^{* * *}\end{array}$ & $\begin{array}{c}0.3957 \\
(10.96)^{* * *}\end{array}$ & $\begin{array}{c}0.3307 \\
(14.15)^{* * *}\end{array}$ & $\begin{array}{c}0.4821 \\
(3.663)^{* * *}\end{array}$ & $\begin{array}{c}0.3986 \\
(15.24) * * *\end{array}$ & $\begin{array}{c}0.3278 \\
(21.13)^{* * *}\end{array}$ & $\begin{array}{c}0.5625 \\
(6.349)^{* * *}\end{array}$ \\
\hline CPI & $\begin{array}{l}-0.0026 \\
(-0.559) \\
\end{array}$ & $\begin{array}{c}-0.0190 \\
(-2.537)^{* *}\end{array}$ & $\begin{array}{l}-0.0003 \\
(-0.053) \\
\end{array}$ & $\begin{array}{c}-0.0651 \\
(-5.040)^{* * *}\end{array}$ & $\begin{array}{r}0.0077 \\
(0.508) \\
\end{array}$ & $\begin{array}{c}-0.0113 \\
(-3.465)^{* * *}\end{array}$ & $\begin{array}{l}-0.0121 \\
(-0.615)\end{array}$ \\
\hline CPI_square & $\begin{array}{c}-9.80 \mathrm{e}-5 \\
(-2.396)^{* *}\end{array}$ & & & & & & \\
\hline GE & $\begin{array}{c}0.0262 \\
(11.10)^{* * *}\end{array}$ & $\begin{array}{r}0.0122 \\
(1.634)\end{array}$ & $\begin{array}{c}0.0305 \\
(8.917)^{* * *}\end{array}$ & $\begin{array}{r}0.0045 \\
(0.561)\end{array}$ & $\begin{array}{c}0.0210 \\
(2.011)^{* *}\end{array}$ & $\begin{array}{c}0.0302 \\
(10.99)^{* * *}\end{array}$ & $\begin{array}{c}0.0173 \\
(2.722)^{* * *}\end{array}$ \\
\hline PS & $\begin{array}{r}0.0012 \\
(1.516)\end{array}$ & $\begin{array}{c}-0.0023 \\
(-1.878)^{*}\end{array}$ & $\begin{array}{r}0.0007 \\
(0.811)\end{array}$ & $\begin{array}{c}0.0085 \\
(1.780)^{*}\end{array}$ & $\begin{array}{r}0.0009 \\
(0.482)\end{array}$ & $\begin{array}{r}0.0012 \\
(0.989)\end{array}$ & $\begin{array}{c}0.0064 \\
(1.947)^{*}\end{array}$ \\
\hline $\mathrm{RL}$ & $\begin{array}{c}-0.0279 \\
(-7.746)^{* * *}\end{array}$ & $\begin{array}{c}0.0095 \\
(3.903)^{* * *}\end{array}$ & $\begin{array}{c}-0.0069 \\
(-2.301)^{* *}\end{array}$ & $\begin{array}{c}-0.0240 \\
(-2.766)^{* * *}\end{array}$ & $\begin{array}{c}0.0317 \\
(2.812) * * * \\
\end{array}$ & $\begin{array}{c}-0.0044 \\
(-1.741)^{*}\end{array}$ & $\begin{array}{l}-0.0137 \\
(-1.445)\end{array}$ \\
\hline RL_square & $\begin{array}{c}0.0002 \\
(5.680)^{* * *}\end{array}$ & & & & & & \\
\hline RQ & $\begin{array}{c}0.0035 \\
(3.322)^{* * *}\end{array}$ & $\begin{array}{r}0.0112 \\
(1.091) \\
\end{array}$ & $\begin{array}{r}0.0015 \\
(0.771) \\
\end{array}$ & $\begin{array}{l}-0.0041 \\
(-1.077)\end{array}$ & $\begin{array}{r}0.0040 \\
(0.618) \\
\end{array}$ & $\begin{array}{c}0.0107 \\
(7.191)^{* * *}\end{array}$ & $\begin{array}{c}-0.0144 \\
(-3.060) * * *\end{array}$ \\
\hline VA & $\begin{array}{c}-0.0180 \\
(-7.322)^{* * *}\end{array}$ & $\begin{array}{c}-0.0097 \\
(-6.125) * * *\end{array}$ & $\begin{array}{c}-0.0346 \\
(-5.187) * * *\end{array}$ & $\begin{array}{r}0.0047 \\
(1.182) \\
\end{array}$ & $\begin{array}{c}0.0263 \\
(3.137)^{* * *}\end{array}$ & $\begin{array}{c}-0.0142 \\
(-2.137)^{* *} \\
\end{array}$ & $\begin{array}{r}0.0057 \\
(1.470) \\
\end{array}$ \\
\hline VA_square & $\begin{array}{c}0.0001 \\
(4.132)^{* * *}\end{array}$ & & $\begin{array}{c}0.0003 \\
(4.110)^{* * *}\end{array}$ & & & $\begin{array}{r}0.0001 \\
(1.346) \\
\end{array}$ & \\
\hline dummy (2012-2017) & $\begin{array}{c}-0.0251 \\
(-3.346)^{* * *}\end{array}$ & $\begin{array}{r}0.0212 \\
(0.908) \\
\end{array}$ & $\begin{array}{c}0.0659 \\
(2.722)^{* * *}\end{array}$ & $\begin{array}{c}-0.1565 \\
(-2.807)^{* * *}\end{array}$ & $\begin{array}{r}0.0264 \\
(0.880)\end{array}$ & $\begin{array}{r}0.0287 \\
(1.461)\end{array}$ & $\begin{array}{l}-0.0244 \\
(-0.290)\end{array}$ \\
\hline Cons & $\begin{array}{c}4.2758 \\
(28.39)^{* * *}\end{array}$ & $\begin{array}{c}3.4173 \\
(3.107)^{* * *}\end{array}$ & $\begin{array}{c}3.3382 \\
(5.971)^{* * *}\end{array}$ & $\begin{array}{c}7.7327 \\
(6.261)^{* * *}\end{array}$ & $\begin{array}{l}-2.9804 \\
(-0.994)\end{array}$ & $\begin{array}{c}3.0486 \\
(6.835)^{* * *}\end{array}$ & $\begin{array}{c}3.1463 \\
(1.835)^{*}\end{array}$ \\
\hline Crossed & 122 & 32 & 60 & 30 & 29 & 61 & 31 \\
\hline Obs. & 1977 & 530 & 974 & 473 & 490 & 996 & 486 \\
\hline & \multicolumn{7}{|c|}{ Auxiliary test statistics } \\
\hline Number of instruments & 230 & 227 & 228 & 227 & 227 & 228 & 227 \\
\hline Test for AR(1) errors & {$[-4.884]^{* * *}$} & {$[-2.014]^{* *}$} & {$[-3.603]^{* * *}$} & {$[-2.783]^{* * *}$} & {$[-2.298]^{* *}$} & {$[-3.324]^{* * *}$} & {$[-2.945]^{* * *}$} \\
\hline Test for AR(2) errors & {$[-0.056]$} & {$[1.752]^{*}$} & {$[-0.495]$} & {$[-1.172]$} & {$[1.662]^{*}$} & {$[0.167]$} & {$[-1.863]^{*}$} \\
\hline Sargan trst & {$[119.6]$} & [31.05] & {$[56.53]$} & {$[25.49]$} & {$[26.84]$} & {$[58.67]$} & {$[27.42]$} \\
\hline Wald (joint) test & {$[17702]^{* * *}$} & {$[3681.5]^{* * *}$} & {$[1383.9]^{* * *}$} & {$[307.33]^{* * *}$} & {$[3049.9]^{* * *}$} & {$[3940.7]^{* * *}$} & {$[403.2]^{* * *}$} \\
\hline
\end{tabular}


Tables (6) and (6-continued) show the estimation results of the study regressions, when using an alternative way in dealing with individual effects, namely the (2-step DPD) method, in order to ascertain the stability and robustness of the results. But before interpreting these results, we first turn to the diagnostic tests appearing below the two tables which confirm the significance of the "AR(1) errors" test at level 1\% in all the regressions. Therefore the null hypothesis suggesting that there is zero autocorrelation from the first degree, should be rejected; and the alternative hypothesis underlining the presence of $A R(1)$ can be accepted. However, AR (1) does not represent a threat to the model validation, while autocorrelation from the second degree -AR(2)- violates the statistical assumption of the estimation methodology. Fortunately $\operatorname{AR}(2)$ does not exist in all the regressions. In addition, Sargan test of overidentifying restrictioons shows that the tools used are valid; and Wald test tells us that there is a general significance of all the explanatory variables as a whole at the $1 \%$ level.

After confirming the validity of the regression results, it can be observed that there is an obvious similarity between the results of the two methodologies. In addition to the positive impact of per capita real wealth in the previous period on per capita real wealth in the current period, as seen in the main regression (1b), we find a negative impact of corruption on sustainable development at the $1 \%$ significance level; whereas we notice a positive impact of all the institutional variables on sustainable development, although this impact varies between a linear or quadratic formula. These results prove the validity of the first and second hypotheses. Furthermore, all the estimation results of the regression (1b) are stationary as evidenced by testing the "Greasing the wheels" hypothesis in the whole sample using the first methodology. These findings are displayed in the regressions (2b) to (6b).

However, a number of differences between the results of the two methodologies can be underscored as follows: In the regressions (1b) to ( $7 \mathrm{~b}$ ) concerning the total study sample, the removal of individual effects has transformed the relationship between the quality of regulatory frameworks and sustainable development into a linear function; and led to the emergence of a U-shaped relationship between (RL) and sustainable development, although their positive connotation does not differ under both methodologies. On the other hand, the connotation of the two methodologies differed to a certain extent regarding the first method for testing the "Greasing the wheels" hypothesis. Hence while the (FEM) methodology lent some support to the validity of the "Greasing the wheels" hypothesis concerning the interaction of corruption with (GE), (PS) and (RQ) variables, the (DPD) methodology gave some support to the validity of the "Greasing the wheels" hypothesis concerning the interaction of corruption with only the (PS) and (VA) variables.

As for the second and third methods of testing the "Greasing the wheels" hypothesis, the results using the DPD methodology were more confusing than the results of the FEM methodology. In regression (7b) which aimed at maximizing the corruption impact function by including the quadratic formula of corruption, the results revealed that the corruption impact function could not be maximized since it was still a negative linear function in the case of all the sample countries, contrary to regression (7a). Under the second method based on maximizing the corruption impact function while classifying the sample countries into groups according to the level of corruption, the only difference - in comparison to the (FEM) methodology - is that no significant corruption impact was found in medium corruption countries as shown in the regression $(9 b)$.

Finally, the third method for testing the "Greasing the wheels" hypothesis has been implemented on the regressions (11b), (12b) and (13b) using the (DPD) methodology. The results contradicted those of the second method using the same methodology. Thus we found no impact of corruption in low and high governance countries; while we observed the emergence of a negative impact of corruption in the medium governance countries. However, the results of the third method using the (FEM) methodology were consistent with the results of the second method using the same methodology. 
In conclusion, the macroeconomic data displayed in the above-mentioned tables prove that corruption is a fundamental obstacle to sustainable development from a weak sustainability perspective. In societies with high levels of corruption, real wealth is collapsing. This is not surprising! Corruption leads to the decrease of investment in both physical and human capital. Moreover, producers tend to violate environmental protection laws and their commitment to use environment friendly technologies or install filters to purify factory exhaust, which leads to increased levels of pollution. Corruption also encourages producers, investors and even governments to make unsustainable use of natural resources.

On the other hand, this evidence carries mixed connotations about the validity of the "Greasing the wheels" hypothesis. In any case, the validity of this hypothesis is basically doubtful; as it considers that corruption enhances efficiency but becomes less effective in the case of low quality institutions. For example Aidt et al. (2008) developed an alternative theory that assumes simply that corruption has less impact on growth in poorly governed countries because things can't get any worse. The "Greasing the wheels" hypothesis also assumes that corruption enhances efficiency at the micro-economic level but may have an opposite effect on the macroeconomic level. Mauro (1995, p.685) states that what is beneficial for the individual may turn out to be harmful for the society.

\section{Additional Robustness Analyses:}

A number of additional tests were carried out in order to verify the robustness and stability of the econometric results. These tests can be summarized as follows: Firstly, the study models were re-estimated using an alternative indicator of corruption based on perceptions, namely the control of corruption indicator, and the results were almost identical. In addition, alternative indicators of the quality of institutions were used; for instance, the freedom indicator around the world issued by Freedom House as an alternative to the voice and accountability indicator; and results did not differ.

Secondly, countries that had large negative growth rates of real wealth per capita during the study period were deleted and there was no significant difference in the reassessed results. Those countries were: Nigeria, Romania, Mozambique, Malawi, Kazakhstan, Angola, Burundi, Bahrain, Guinea, Laos, Lebanon, Liberia, Oman, Trinidad and Tobago and the Republic of Congo. Thirdly, a number of alternative statistical methods were used in order to obtain robust and unbiased estimates of corruption impact; such as the Quantile Regression with Cross-section Fixed Effect method, a strong instrument against residual non-normality; and the Robust Least Square "MM-estimation" method used against outlier values. Although this last method did not affect our findings concerning corruption or institutions, it yielded conflicting results regarding the extent to which the "Greasing the wheels" hypothesis can be considered valid.

\section{Results and Future Studies:}

Social infrastructure has been recently considered one of the most critical determinants of economic growth, with its importance even surpassing that of traditional determinants such as the accumulation of financial and human capital and technological progress. This is due to the fact that social infrastructure provides the environment within which these traditional determinants operate and determines their effectiveness in achieving economic development.

In this regard, the majority of research studies confirmed that corruption is one of the most salient features shaping the social infrastructure of different societies. To the extent that we have recently noticed the emergence of a unified language linking issues of corruption to good governance and development; insofar as corruption is considered a deviation from strong and efficient governance systems or a weakness in governance. 
Therefore, this paper has tried to study the impact of corruption, as one of the most important features of social infrastructure, on sustainable development within the framework of institutional quality (good governance) in order to eliminate the problem of the omitted-variable bias, while examining the adequacy of the "Greasing the wheels" hypothesis for explaining the relationship between corruption and sustainable development.

The main finding of the study is that corruption is a major obstacle to sustainable development, while the rest of the social infrastructure (other institutional) variables are powerful tools for achieving sustainable development from a weak sustainability perspective. Moreover, the infrastructure impact on sustainable development is robust and stable. Some of the study tests also revealed that the impact of corruption on sustainable development is not linear; and this result is consistent with the economic logic stating that: "A little corruption is useful or harmless, while much of it is very harmful."

On the other hand, verifying the validity of the "Greasing the wheels" hypothesis showed conflicting results; whether when using different testing methods and methodologies or various indicators of corruption. Therefore, these results cannot be relied upon to validate the "Greasing the wheels" hypothesis concerning the relationship of corruption to sustainable development. This controversy may in fact support the hypothesis that corruption does not enhance economic efficiency.

For further research, the current study recommends studying the relationship between corruption and sustainable development from a strong sustainability perspective, as measured by the "ecological footprint of each individual" indicator; in addition to examining the "Greasing the wheels" hypothesis using several indicators of corruption, based on perceptions and experience. 


\section{References:}

- $\quad$ Aidt, T.; Dutta, J. \& Sena, V. (2008). “Governance Regimes, Corruption \& Growth: Theory \& Evidence", Journal of Comparative Economics, 36 (2), 195-220.

- $\quad$ Aidt, T. S. (2009). "Corruption, Institutions and Economic Development", Oxford Review of Economic Policy, 25 (2), 271-291.

- $\quad$ Aidt, T. S. (2011). "Corruption \& Sustainable Development", In: International Handbook on the Economics of Corruption, 1.

- $\quad$ Aliyu, S. U. R. \& Elijah, A. O. (2008). “Corruption and Economic Growth in Nigeria: 1986-2007.

- $\quad$ Baum, C. F. \& Christopher, F. (2006). An Introduction to Modern Econometrics Using Stata. Stata Press.

- Braguinsky, S. (1996). “Corruption \& Schumpeterian Growth in Different Economic Environments", Contemporary Economic Policy, 14 (3), 14-25.

- $\quad$ Brunetti, A.; Kisunko, G. \& Weder, B. (1998). “Credibility of Rules and Economic Growth: Evidence From a worldwide Survey of the Private Sector", The World Bank Economic Review, 12 (3), 353384.

- $\quad$ Chen, H.; Hao, Y.; Li, J. \& Song, X. (2018). The Impact of Environmental Regulation, Shadow Economy, and Corruption on Environmental Quality: Theory and Empirical Evidence from China", Journal of Cleaner Production, 195, 200-214.

- $\quad$ Fuller, W. A. (2009). Introduction To Statistical Time Series, (Vol. 428). John Wiley \& Sons.

- Gujarati, D. N. (2003). Basic Econometrics. $4^{\text {th }}$ ed. McGraw Hill Gujarati, DN.

- Gyimah-Brempong, K. \& de Gyimah-Brempong, S. M. (2006). “Corruption, Growth and Income Distribution: Are There Regional Differences?", Economics of Governance, 7 (3), 245-269.

- Hall, R. E. \& Jones, C. I. (1999). “Why Do Some Countries Produce So Much More Output Per Worker Than Others?", The QuarterlyJournal of Economics, 114, (1), 83-116.

- Heckelman, J. C. \& Powell, B. (2010). "Corruption \& the Institutional Environment for Growth", Comparative Economic Studies, 52 (3), 351-378.

- Ishola Mobolaji, H. \& Omoteso, K. (2009). “Corruption \& Economic Growth in Some Selected Transitional Economies", Social Responsibility Journal, 5 (1), 70-82.

- $\quad$ Knack, S. \& Keefer, P. (1995). “Institutions \& Economic Performance: Cross-Country Tests Using Alternative Institutional Measures", Economics \& Politics, 7 (3), 207-227.

- Lambsdorff, J. G. (1999). Corruption in Empirical Research: A Review. Transparency International, Processed, 6.

- $\quad$ Lameira, V. D. J.; Jr, W. L. N.; Amaral-Baptista, M. A.; Pereira, R. G. \& Quelhas, O. L. G. (2013). “Corruption, Governance \& Sustainable Development", International Journal of Monetary Economics \& Finance, $6(2-3), 213-231$

- Lash, N. A. (2004). “Corruption \& Economic Development", The Journal of Economic Asymmetries, $1(1)$.

- $\quad$ Leite, M. C. \& Weidmann, J. (1999). Does Mother Nature Corrupt: Natural Resources, Corruption, \& Economic Growth. International Monetary Fund.

- $\quad$ Mauro, P. (1995). “Corruption \& Growth”, The Quarterly Journal of Economics, 681-712.

- Mauro, P. (1997). Why Worry about Corruption?. (Vol. 6). International Monetary Fund. 
Mo, P. H. (2001). “Corruption \& Economic Growth", Journal of Comparative Economics, 29 (1), 66-79.

- $\quad$ Morse, S. (2006). "Is Corruption Bad for Environmental Sustainability? A Cross-National Analysis", Ecology \& Society, 11 (1), 22.

- Méndez, F. \& Sepúlveda, F. (2006). “Corruption, Growth \& Political Regimes: Cross Country Evidence", European Journal of Political Economy, 22 (1), 82-98.

- Méon, P. G. \& Weill, L. (2010). "Is Corruption an Efficient Grease?", World Development, 38 (3), 244-259.

- Olson, M. (1996). “Distinguished Lecture on Economics in Government: Big Bills Left on the Sidewalk: Why Some Nations are Rich, and Others Poor", Journal of Economic Perspectives, 10 (2), 3-24.

- Pellegrini, L. \& Gerlagh, R. (2004). “Corruption's Effect on Growth \& Its Transmission Channels". Kyklos, 57 (3), 429-456.

- Pellegrini, L. (2011). “Causes of Corruption: A Survey of Cross-Country Analyses and Extended Results", In: Corruption, Development \& The Environment, (pp. 29-51). Springer Netherlands.

- $\quad$ Romer, D. (2012). Advanced Macroeconomics. $4^{\text {th }}$ ed. Mc-Graw Hill Companies. Inc. Singapore.

- Sinha, A.; Gupta, M.; Shahbaz, M. \& Sengupta, T. (2019). "Impact of Corruption in Public Sector on Environmental Quality: Implications for Sustainability in BRICS and Next 11 Countries", Journal of Cleaner Production.

- $\quad$ Tanzi, M. V. \& Davoodi, M. H. R. (2000). Corruption, Growth and Public Finances (Epub), (No. 0-182). International Monetary Fund.

- Tanzi, V. (1998). "Corruption around the World: Causes, Consequences, Scope and Cures", Staff Papers, 45 (4), 559-594.

- $\quad$ UNDP. (2008). Corruption \& Development. UNDP.

- Venard, B. (2013). "Institutions, Corruption \& Sustainable Development", Economics Bulletin, 33 (4), 2545-2562.

- $\quad$ Wei, S. J. \& Zeckhauser, R. (1999). „Dark Deals \& Dampened Destinies: Corruption \& Economic Performance", Japan \& The World Economy, 11(3), 443-454.

- $\quad$ Zhang, Y. J.; Jin, Y. L.; Chevallier, J. \& Shen, B. (2016). “The Effect of Corruption on Carbon Dioxide Emissions in APEC Countries: A Panel Quantile Regression Analysis", Technological Forecasting \& Social Change, 112, 220-227.

- Kuloglu, A.; Lobont, O. R. \& Topcu, M. (2012). A Question of Causality between Political Corruption, Economic Freedom and Economic Growth in Europe.

- Méon, P. G. \& Sekkat, K. (2005). "Does Corruption Grease or Sand the Wheels of Growth?", Public Choice, 122 (1-2), 69-97. 